\title{
Carbon Nanotube-Based Thin Films: Synthesis and Properties
}

\author{
Qiguan Wang ${ }^{1}$ and Hiroshi Moriyama ${ }^{2}$ \\ ${ }^{1}$ Research Center for Materials with Integrated Properties. Present Affiliation: School of \\ Materials and Chemical Engineering, Xi'an Technological University \\ ${ }^{2}$ Research Center for Materials with Integrated Properties and \\ Department of Chemistry, Toho University, \\ ${ }^{1}$ China \\ 2Japan
}

\section{Introduction}

Thin films composed of carbon nanotubes (CNTs) are an emerging class of material with exceptional electrical, mechanical, and optical properties that can be readily integrated into many novel devices.[1-4] These features suggest that CNT films have potential applications as conducting or semiconducting layers in different types of electronic, optoelectronic, and sensor systems. To understand better how to obtain these films and how to fabricate devices using them, film-forming techniques and experimental work that reveals their collective properties are of importance from fundamental and applied viewpoints.

CNTs are a well-known class of material, whose molecular structure can be considered as a series of graphene sheets rolled up in certain directions designated by pairs of integers.[5] In fact, the exceptional electrical, mechanical, optical, chemical, and thermal properties have terms with their unique quasi-one-dimensional structure, atomically monolayered surface, and extended curved $\pi$-bonding configuration.[6-10] For example, with a different chirality and diameter, an individual single-walled nanotube (SWNT) can be either semiconducting, metallic, or semimetallic, and they can be used as active channels in transistor devices because of their high mobilities (up to about $10000 \mathrm{~cm}^{2} \mathrm{Vs}^{-1}$ at room temperature),[11] or as electrical interconnectors, because of their low resistivities,[12,13] high current-carrying capacities (up to about $10^{9} \mathrm{~A} \mathrm{~cm}^{-2}$ ), [14] and high thermal conductivities (up to $3500 \mathrm{~W} \mathrm{~m}^{-1}$ $\mathrm{K}^{-1}$ ).[15] With their unique structure, CNTs are stiff and strong, with Young's moduli in the range of 1-2 $\mathrm{TPa}$. Their fracture stresses can be as high as $50 \mathrm{GPa}$, exhibiting a densitynormalized strength 50 times larger than that of steel wires.[16] In addition, the weightnormalized surface area of CNTs can be as high as $1600 \mathrm{~m}^{2} \mathrm{~g}^{-1}$,[17] thereby rendering them suitable for various sensor applications. CNTs can be used in many areas, ranging from nanoscale circuits,[18,19] to field-emission displays,[20] to hydrogen-storage devices,[21,22] to drug-delivery agents,[23,24] to light-emitting devices,[25,26] thermal heat sinks,[27,28] electrical interconnectors,[29] and chemical/biological sensors.[30]

It should be noted that the electronic features of CNTs are among their most important properties. Because of their high mobilities and ballistic transport characteristics, CNT films 
have been considered as the best replacement for $\mathrm{Si}$ in future devices.[31,32] Although most CNT films show a structure of completely random networks, these films are still attractive in large-area-coverage electronics, such as macroelectronics[33], mechanical flexibility/stretchability, and optical transparency.

\section{CNT thin-film synthesis}

Formation of thin films of CNTs is a necessary step to their fundamental study and use in applications. For the different fabrication techniques, how to control the tube density, the overall spatial layouts, their lengths, and their orientations must be understood, because these parameters significantly influence the collective electrical, optical, and mechanical properties.

\subsection{Chemical vapor deposition growth}

Chemical vapor deposition (CVD) is a direct method to obtain CNT films on solid substrates. Generally, $\mathrm{Fe}$ and $\mathrm{Co}$ are used as catalysts with $\mathrm{CO}$, ethylene, or ethanol as the feedstock. To prevent the pyrolysis of carbon to form soot,[34] some hydrogen is usually added. Typical processing conditions involve flowing $\mathrm{H}_{2}$ at $400-1000 \mathrm{sccm}$ and $\mathrm{CO}$ at 200$1000 \mathrm{sccm}$ with the temperature in the range $600-900{ }^{\circ} \mathrm{C}$ under argon.

CNT films formed using the CVD method show high levels of structural perfection, long average tube lengths, high purity, and relative absence of tube bundles. Moreover, the density, morphology, alignment, and position of tubes are also easily controlled in the CVD method. As is well known, the density value (D) is important because of its strong influence on the electrical properties of films. Experimental data demonstrate that the composition and flow rate of the feed gas can be used to control D. Compared with the case of methane, $\mathrm{D}$ for films obtained using ethanol as the carbon feedstock significantly increases. This is possibly because of the ability of $\mathrm{OH}$ radicals in ethanol to remove amorphous carbon seeds from catalytic sites in the early stages of growth.[35] The nature of the catalyst is also important. The multiple-component catalysts of $\mathrm{Fe} / \mathrm{Co} / \mathrm{Mo}$ [36-38] yield densities higher than those obtained from single Fe nanoparticles, because the former has an increased surface area, pore volume, and catalytic activity. In addition, the concentration of the catalyst, the size,[39-41] composition of the catalyst, growth temperature, pressure, and time can also affect properties such as $\mathrm{D}$, diameter distributions, chiralities, and average tube length.[42]

By using different driving forces from electrical fields,[43,44] laminar flow of feed gas,[45$48]$ and surface atomic steps, $[49,50]$ as well as anisotropic interactions between CNTs and single-crystalline substrates,[51-53] high alignment can be obtained. For example, electric fields $\left(>1 \mathrm{~V} \mathrm{\mu m}^{-1}\right)$ can provide high torques, which are sufficiently large to limit thermal motions of growing CNTs, even with high-temperature growth conditions, thereby yielding field-aligned SWNTs. The degree of alignment is mainly controlled by the surface quality, cleanliness, and the physics of the underlying interactions. With catalysts patterned into small regions on a solid substrate, both perfect levels of alignment and the highest levels of $\mathrm{D}$ can be achieved; thus the tubes grow primarily in regions of the substrate with reacted catalyst particles.[54]

Apart from controlling the flow of feed gas, utilization of some templates is another effective method to synthesize aligned CNT films, where the template is usually alumina membranes 
with regularly distributed pores. In this process, the CVD reactor consists of a quartz tube placed within a tube furnace, in which an alumina template membrane is placed vertically in the CVD reactor, and the reactor temperature is kept at about $670{ }^{\circ} \mathrm{C}$, under argon flow. After flowing ethylene pyrolyzes to yield CNTs on the pore walls as well as thin carbon films on both faces of the membrane, the furnace is turned off and allowed to cool to room temperature. Thus, a parallel array of nanotubes connected together by the carbon surface film can be obtained after dissolution of the alumina template.

Shortly after the discovery of CNTs, several growth methods were developed to synthesize different forms of CNTs in a controlled manner, such as arc discharge,[55] pulsed laser deposition,[56] and catalytic CVD (CCVD).[57] For CCVD, there are several specialized versions, such as hot wire,[58] plasma-enhanced,[59] and template [60] CCVD, which are the most commonly utilized techniques today. Among those methods listed above, CCVD techniques show the great advantage that when applied on prepatterned substrates or catalyst particles, well-aligned CNT films similar to the prepatterned template can be made.[61,62] This feature is essential for applications with special requirements of high thermal conductivity and outstanding mechanical or electrical properties.

Through a later-developed floating catalyst CVD (FCCVD) technique,[63] strong, highly conducting, and large-area transparent SWNT films can be synthesized. In contrast to the typical CVD method, a sublimed mixture of ferrocene/sulfur powder heated to $65-85{ }^{\circ} \mathrm{C}$ was used as the catalyst source, and flowed into a reaction zone by a mixture of $1000 \mathrm{sccm}$ argon and 1-8 sccm methane. After 30 min growth, thin films with a thickness of $100 \mathrm{~nm}$ formed in the high-temperature zone (over $600^{\circ} \mathrm{C}$ ) of the quartz tube, which can be easily peeled off. Systematic tests reveal that the electrical conductivity of the CNT films is over $2000 \mathrm{~S} / \mathrm{cm}$ and the strength can reach $360 \mathrm{MPa}$, which are both enhanced by more than one order compared with the films made from solution-based processes. It is the long interbundle connections from the firm bondings between CNT bundles that make their conductivity and strength so intriguing.

The next method for obtaining a vertically aligned CNT forest was a plasma-enhanced CVD (PECVD) technique.[64,65] Although a variety of different methods are also currently available, the PECVD process is the only technique that produces perfectly aligned, untangled CNTs. For the PECVD process, there are two main steps. First, the formation of nickel (Ni) catalyst islands on an oxidized $(20 \mathrm{~nm})$ silicon substrate through sintering at 650 ${ }^{\circ} \mathrm{C}$. Second, nanotube growth from these discrete catalyst islands in a DC plasma discharge (bias $-600 \mathrm{~V}$ ) of acetylene and ammonia, at a pressure of 4 Torr. The initial thickness of the $\mathrm{Ni}$ catalyst layer controls the nanotube diameter and areal density. The plasma deposition time controls the nanotube height. A typical nanotube forest grown through this process has an areal density of 10 MWNTs per $\mu \mathrm{m}^{2}$, with the vertical MWNTs having a mean diameter of $50 \mathrm{~nm}$ and a height of $2 \mu \mathrm{m}$.

At present, CVD methods are considered to be well suited for preparation of vertically aligned CNT arrays. The properties of the supporting substrates on which the nanotube films are grown often play a critical role in their applications. Moreover, only a limited variety of substrate materials are suitable for nanotube CVD growth processes, because the typical CVD growth temperature is higher than $600{ }^{\circ} \mathrm{C}$. The interaction between the catalyst and substrate controls growth of nanotubes. Si and quartz wafers are the two substrate materials most commonly used in CVD. By using replication of a growth step and an oxidation step, single-layer or multilayer freestanding nanotube films can be synthesized. In this process, a very low concentration of water vapor can act as a catalyst promoter during nanotube growth, and also as a weak oxidant to etch the nanotube ends after growth. The 
oxidation step plays the role of an etching process that detaches the nanotube film from the substrate, yielding a freestanding superhydrophobic film. This vertically aligned freestanding CNT film could possibly find practical applications in many devices, such as energy storage, filtration, and the fabrication of superhydrophobic surfaces.

\subsection{Electrophoretic deposition}

The characteristic of inherent insolubility for CNTs has delayed their film formation from a wet method such as drop drying or electrophoretic deposition. After solubility improvement of carbon nanotubes by using two possible approaches of noncovalent $[66,67]$ and covalent functionalization,[68-72] several wet methods have been proposed to prepare thin films of CNTs with controlled morphology and desired function. Compared to the CVD method, the wet methods like drop drying, electrophoretic deposition, Langmuir-Blodgett technique and self-assembling method, which are generally operated at ambient pressure and room temperature, are considered to be simpler and easier, which have attracted more research interest.

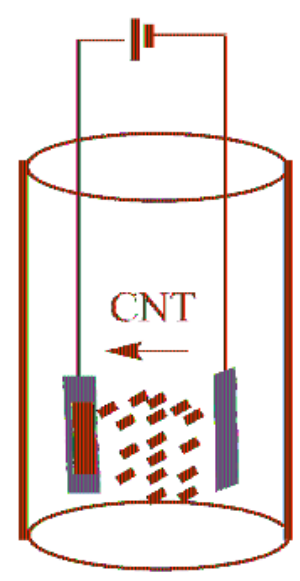

Fig. 1. Schematic diagram of the electrophoresis process for the film deposition of CNTs.

Electrophoretic deposition (EPD) has been shown to be a convenient method of fabricating thin films of CNTs with the desired thickness and excellent macroscopic homogeneity (Figure 1). EPD is fundamentally a combination of two processes, electrophoresis and deposition. In the first step, particles suspended in a liquid are forced to move toward an electrode by applying an electric field. In the second step, the particles collect at the electrode and form a coherent deposited film.[73-75] The applied electric field and deposition time are the crucial parameters to control the CNT deposition yield and thickness. A mathematical model based on Hamaker's law can be used to predict the kinetics of EPD of CNTs. In particular, different local microstructures of CNT deposits lead to variations of Young's modulus and hardness, which are attributed to differences in the packing density of CNTs. The great advantage of the EPD method lies in its simplicity. It is a cost-effective method and offers monolithic or composite coatings with complex shapes and surface patterns. In addition, the deposition rate in EPD is very fast, as much as two orders of magnitude higher than other suspension-based processes, such as slip casting. 
By a combination of EPD and fissure formation techniques, a thin film of CNTs was deposited on a Ti substrate from an aqueous mixture of CNT and sodium dodecylsulfate detergent (SDS). This horizontally aligned CNT film can be used as a good field emitter.

Assisted by ultrasonic treatment after EPD, oriented SWNT bundles with high density can be formed on a gold electrode by EPD. Applying ultrasonic energy resulted in the deposited SWNT bundles reassembling and orienting normal to the electrode. To get this morphology, experimental parameters, including the gap between the two electrodes, strength of the electric field, and lengths of the CNTs, are important. This combined method may prove useful in the fabrication of CNT-based electron emission devices or fuel-cell electrodes.

\subsection{Drop drying from solvent}

Techniques to form CNT thin films from solution suspensions are attractive because they can be cost-effectively scaled to large areas compatible with various substrates. They generally involve a reliable means of surfactant wrapping, to form stable solutions of CNTs, followed by evaporation of solvent (Figure 2),[76,77] or specific interactions to fabricate a film. However, a major challenge for solution deposition methods is that the low solubility and strong intertube interaction of CNTs make it difficult to obtain robust thin films with uniform moderate-to-high coverage. By means of CNT-substrate chemical interactions, these problems can be reduced to some extent, but they reduce the range of substrates and surfactants that can be used. In addition, these interactions can have adverse effects on CNT properties.

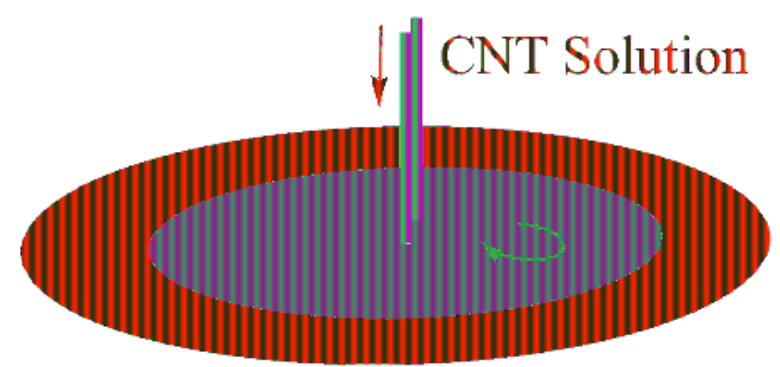

Fig. 2. Schematic diagram of the drop-drying process for the film fabrication of CNTs.

A major advantage of solution methods is that they can yield thin films directly at room temperature using CNTs formed with bulk synthesis procedures, in a manner compatible with patterning techniques such as thermal, piezoelectric, or electrohydrodynamic jet printing.[78,79] A key disadvantage is that the CNTs must first be dispersed in solution suspensions. This step often requires processes including high-power ultrasonication or strong-acid treatments, which degrade the electrical properties and reduce the average lengths of the tubes. In addition, the coated surfactants introduce unwanted organic contaminants for electronic devices.

It is reported that through the addition of liquids that are miscible with the suspending solvent and that also interact with the surfactant, this controlled flocculation $(\mathrm{cF})$ process can actively drive CNTs out of solution in the desired manner. When the fluids are confined close to the surface of a target substrate during mixing, uniform films of CNTs without significant presence of bundles can be produced. Several different methods are expected to 
help this confinement. In one case, simultaneously introducing methanol and aqueous suspensions of CNTs onto a rapidly spinning substrate can lead to a confined CNT suspension as a thin liquid film close to the substrate surface.[80] The shear flows by spinning help to confine the two liquids vertically and to mix them rapidly, giving uniform coatings of individual or minimally bundled CNTs. Laminar flows in microfluidic channels provide the confinement.[81] The formation of fluids flowing side by side in a microchannel is another effective approach to obtaining thin CNT films. This $\mathrm{cF}$ method can form films ranging from monolayer to thick, multilayer coatings by simply increasing the duration of the procedure or the relative amount of CNT suspension.

Processing of CNT-based materials into engineered macroscopic materials is still in its infancy. Evaporation of drops on substrates has been used for solution deposition of CNTs onto nonporous substrates. The moving contact line of a drying drop could be used to form aligned pattern films of CNTs. Evaporation of solvent leads to a local increase in concentration of the suspension, and a very thin gelled crust is formed at the free surface. Crust formation because of solvent mass transfer across an interface qualitatively follows de Gennes' theory. The phenomenon of crusting may be exploited to fabricate thin crusts and coatings of CNTs on substrates.

Solution deposition can also be used to fabricate simple devices such as field-effect transistor (FET) architectures. To form the gate layer, a suspension of CNTs was sprayed onto a supporting substrate to form a dense nanotube network.[82] The suspension consisted of a concentration of around $1 \mathrm{mg} / \mathrm{mL}$ of nanotubes in a $1 \%$ solution of aqueous SDS. The substrate should be heated after spraying to prevent droplets from forming on the surface and to inhibit flocculation of the nanotubes. Rinsing the substrate by water then removes the SDS. Because the density of the nanotube network in the conducting channel can be tuned by controlling the number of drops of nanotube suspension adsorbed, it is much easier to get reproducible devices than with CVD methods.

If CNTs suspended in a variety of solvents are airbrushed onto a substrate placed on a hot plate at $100-150{ }^{\circ} \mathrm{C}$, nanotube films with a wide range of thicknesses can be obtained by ensuring that all films have a constant, low ohmic resistance.

\subsection{Langmuir-Blodgett technique}

Because chemically solubilized CNTs possess good surface spreading properties at the air/water interface, optically homogeneous thin films have been prepared from the Langmuir-Blodgett (LB) technique (Figure 3). Deposition can be performed in a layer-bylayer (LBL) fashion for more layers either by horizontal lifting or vertical dipping, which allows ready control of the film thickness. This technique exhibits great feasibility. The homogeneous thin films can be synthesized in the presence or absence of assistant polymers employing either horizontal lifting or vertical dipping. By means of the good film-forming properties of poly( $\mathrm{N}$-dodecylacrylamide) (PDDA), a stable monolayer of polymer-dispersed chemically solubilized SWNTs can be formed on the water surface, from which thin films of CNTs can be fabricated, by using the LB technique.[83-86] After finely tuning the conditions for the pretreatments and chemical solubilization of SWNTs, fabrication of homogeneous LB films of SWNTs even without using the matrix polymer is possible. More importantly, SWNTs in these films are found to be highly oriented in a specific direction. Polarized absorption spectroscopy and atomic force microscope (AFM) observations demonstrate that the tubes are oriented in the direction of the trough barrier in the case of horizontal lifting or in the dipping direction in the case of vertical dipping. These observations are attributed to compression-induced or flow-induced orientations, respectively, with the latter found to be 
much stronger than the former. The attainment of homogeneous thin films of SWNTs with a controllable thickness and tube orientation should be an important basis for the future development of their technological applications.

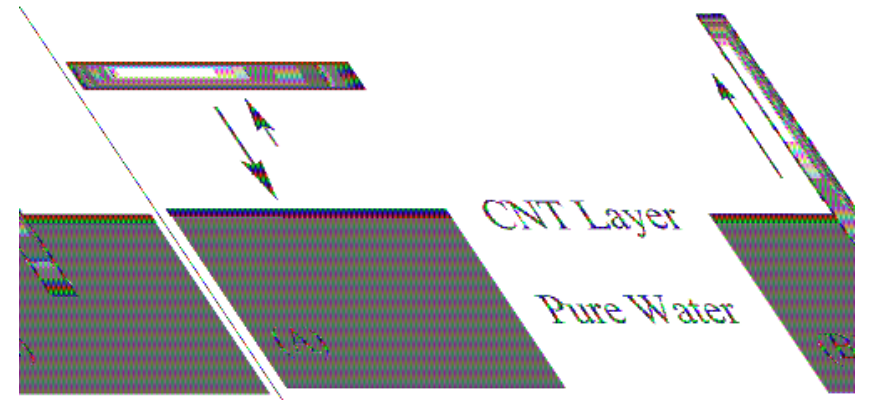

Fig. 3. Scheme for the preparation of Langmuir-Blodgett CNT films by the horizontal-lifting (A) and vertical-dipping (B) methods. Reproduced with permission from Y. Kim, N.

Minami, W. Zhu, S. Kazaoui, R. Azumi, M. Matsumoto, Jpn. J. Appl. Phys. 2003, 42, 7629.

Copyright 2003 The Japan Society of Applied Physics.

\subsection{Self-assembling method (SAM)}

By electrostatic and van der Waals interactions, LBL assembly (Figure 4A) reduces the phase segregation and makes different components highly homogeneous, well dispersed, and interpenetrated.[87] Alternating adsorption of monolayers of components attracted to each other results in a uniform growth of films. Recently, more detailed experiments demonstrated that it can be very successfully applied to the preparation of CNT films. The LBL assembly technique results in a nanotube content in the vicinity of $50 \%$, which is significantly higher than in a typical nanotube composite.

By chemical modification, CNTs can show acid and base groups, which can be treated much as weak polyelectrolytes such as poly(acrylic acid) or poly(allylamine hydrochloride). Based on the LBL assembly method, negatively and positively charged CNTs of CNT-COOH and $\mathrm{CNT}-\mathrm{NH}_{2}$ have been alternatively adsorbed onto a substrate to form an all-carbon film, which consists of well-dispersed CNTs.[88] Like other multilayer assemblies, this $100 \%$ CNT thin film shows $\mathrm{pH}$-dependent thickness and surface topology, which are characteristics of LBL thin films of weak polyelectrolytes. The surface topology and the inner structure of this thin film are interconnected random network structures with physical entanglements. Sheet resistance and cyclic voltammetry $(\mathrm{CV})$ measurements show that these films are promising electrode materials for high-power and high-energy electrochemical devices.

Self-assembly of true chemical linkages between the molecules and the substrates (Figure $4 \mathrm{~B})$ is another low-cost process for formation of functional molecules. Van der Waals interactions between neighboring chemisorbed molecules generally lead to long-distance ordering in the first monolayer. Self-assembly from solution or the gaseous state can result in very good coverage. By using this SAM method, an ordered CNT film with a perpendicular orientation can be prepared on gold surfaces. The as-grown nanotubes were first chemically functionalized by thiol groups. The ordered assembly of CNTs was accomplished by their spontaneous chemical adsorption on gold via Au-S bonds. The adsorption kinetics of the nanotubes was very slow in comparison with conventional alkane thiols. The adsorption rate varied inversely with tube length. The nanotubes tend to form 
bundles as the adsorption propagates, following a "nucleation adsorption mechanism." Functionalized CNTs perpendicular to the surface can be assembled on various substrates via a predesigned bonding nature. For example, carboxylic acid-terminated CNTs assemble on an amino-terminated silicon and silver surface via electrostatic interaction or chemical bonding such as the surface condensation reaction.[89]

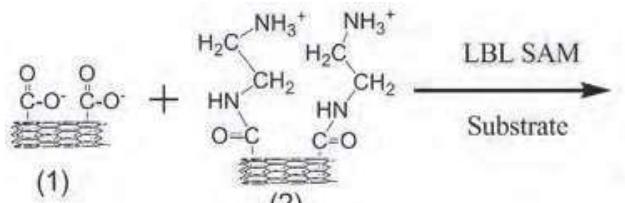

(2)

(A)

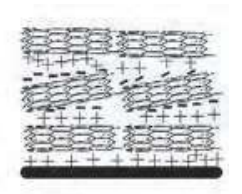

CNT multilayer

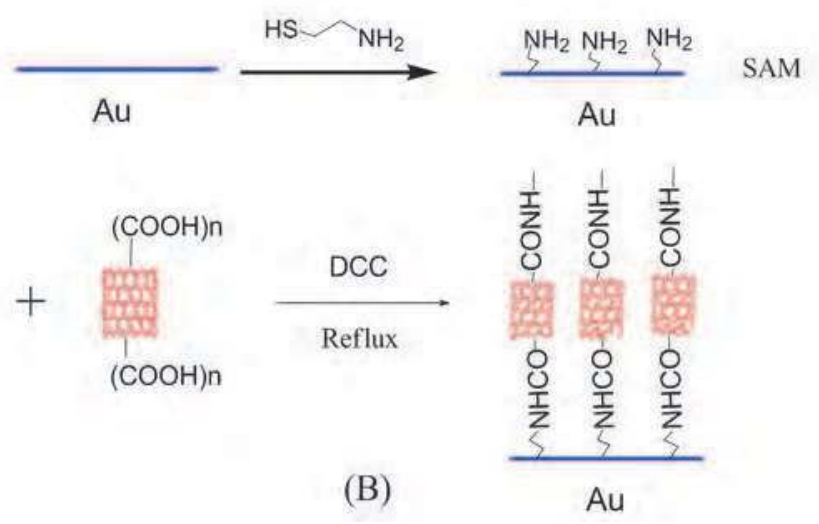

Fig. 4. Scheme for the preparation of SAM CNT films by the electrostatic-interaction (A) and chemical-bonding (B) methods.

With the assistance of an electric field, highly aligned CNT thin films can be fabricated by the chemical assembly approach.[90] With increase in the electric field, the assembling kinetics of CNTs is remarkably speeded up, and the packing density can even exceed the saturated density of the conventional assembly method by a factor of four. The molecular dynamics simulation results illustrated the alignment of CNTs with their long axes along the electric flux in solution, leading to the increase in packing density and efficiency. Under a d.c. electric field, the CNTs are aligned with their long axes along the electric flux and drift toward the anode substrate with higher velocity, leading to the increase in packing density by overcoming the steric hindrance of the "giant" CNTs and the effective decrease in assembling time.

\subsection{Electropolymerization}

Electropolymerization of polymerizable monomers is an effective method for assembling polymer films on electrode surfaces, and the electropolymerization of monomer- 
functionalized giant metal nanoparticles, for example, pyrrole-capped Au nanoparticles,[91] was reported to yield a two-dimensional (2-D) nanoparticle array. Recently, the preparation of $p$-mercaptoaniline-capped CdS nanoparticles and their electropolymerization on a $\mathrm{Au}$ electrode in a monolayer assembly has been successfully achieved.
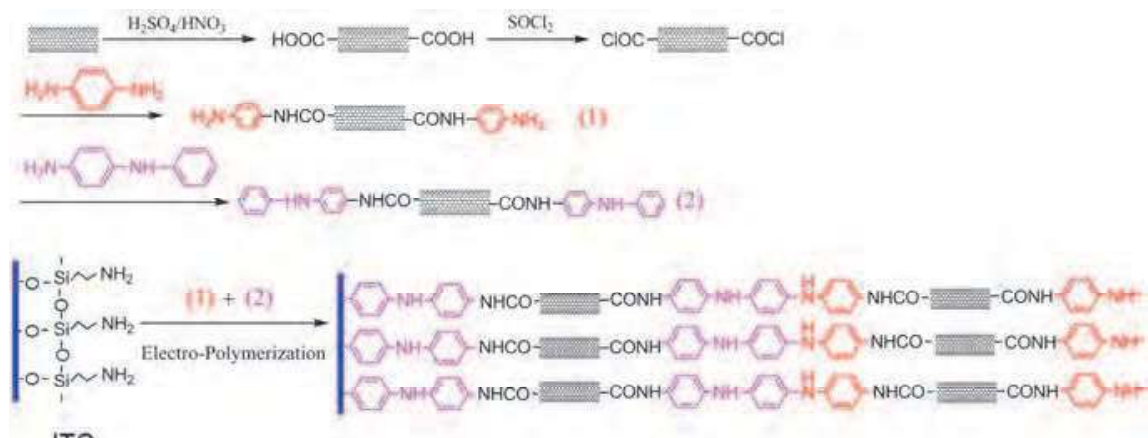

ITO

SWNT film grafted to ITO

Fig. 5. Scheme for the preparation of CNT films by using the electropolymerization method.

Similarly, a CNT film can be generated by using the electropolymerization method, if CNTs were correctly modified by some polymerizable groups such as phenylamine. The oxidized multiwalled nanotube was functionalized with $p$-phenylenediamine, which gave functional groups on the surface. In our group, an SWNT film on indium-tin oxide (ITO) was prepared by electropolymerizing the $N$-phenyl-1,4-phenylenediamine-modified SWNT in aqueous solution (Figure 5). The CNT film showed a homogeneous structure (Figure 6), where the SWNTs were interconnected to form a dense film, which provided another path for ease of preparing CNT film with good mechanical properties.

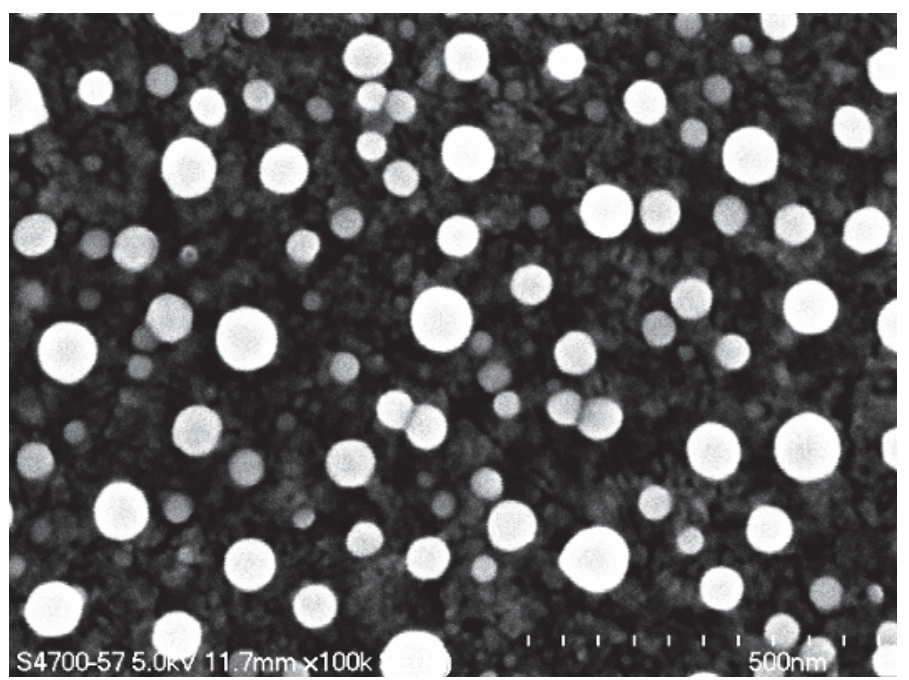

Fig. 6. SEM images of CNT films prepared by using the electropolymerization method. 


\subsection{Vacuum-filtering method}

Probably, compared with the other methods, the vacuum-filtering method (Figure 7) is regarded as the simplest process for the fabrication of ultrathin, transparent, optically homogeneous, electrically conducting films composed of pure CNTs.[92] This process is quite simple, containing three steps: vacuum filtering a dilute, surfactant-based suspension of purified nanotubes onto a filtration membrane to form a homogeneous film on the membrane, then washing away the surfactant with purified water to allow film formation of pure CNT, followed by dissolving the filtration membrane in solvent. From the above, this filtration method has several advantages: (i) as the nanotubes accumulate, the generated filter cake acts to impede the permeation rate, which can tune the local permeation rate and associated deposition rate automatically. Therefore, homogeneity of the films is guaranteed. (ii) Under vacuum, the nanotubes tend to lie straight, gaining maximum overlap and interpenetration within the film as they accumulate. This yields maximum electrical conductivity and mechanical integrity throughout the films. (iii) The film thickness is controlled, with nanoscale precision, by the nanotube concentration and volume of the suspension filtered.

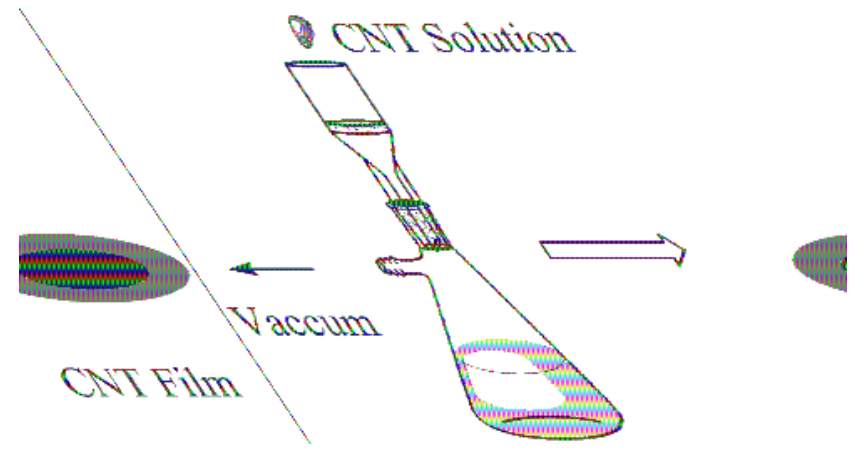

Fig. 7. Scheme for the preparation of CNT films by using the vacuum-filtering method.

In addition, through a simple postdeposition method, the conductivity of the obtained CNT film can be improved via exposure to nitric acid and thionyl chloride. Sheet resistance of CNT thin films is decreased by a factor of five via exposure to thionyl chloride. This enhancement in transport properties upon $\mathrm{SOCl}_{2}$ treatment is related to the formation of acyl chloride functionalities. The obtained CNT films are more flexible than ITO, and can be a replacement for those expensive semiconductors.

\section{CNT-based thin films}

\subsection{Nonconjugated molecule-CNT thin films}

Nonconjugated molecule-CNT thin films are generally prepared by two approaches: solution casting and LBL assembly. The driving forces include electrostatic interactions,[9395] hydrogen bonding, $[96,97]$ charge-transfer interactions,[98] and coordination bonding.[99]

For construction of CNT composites, LBL assembly allows excellent control of thickness and composition and diminished phase segregation compared with other methods.[100] So far, all LBL composites containing CNTs have been constructed via electrostatic 
interactions[101] or hydrogen bonding.[102] However, covalent cross-linking between SWNT and polymer is needed for strengthened composite films. By using some special reactions such as covalent linkage under UV irradiation, the electrostatic LBL film of SWNT-poly(sodium 4-styrenesulfonate) (PSS) and a diphenylamine-4-diazoresin can be converted to a cross-linked film. The SWNT-PSS was $55 \mathrm{wt} \%$ SWNT.[103] Apart from the increase in mechanical strength, the resistance of the film toward etching by polar solvents increased significantly after irradiation.

By using spin coating with a mixture that consists of a solvent with low volatility, transparent electrically conductive films of CNTs and thermoplastic polymer poly(methyl methacrylate) (PMMA) can be obtained, which may replace ITO.[104]

For the LBL process, poly(diallyldimethylammonium chloride) (PDDA) can be used as a model for preparation of polymer/CNT films.[105] A clean hydroxy-bearing silicon wafer is first dipped into a $1 \mathrm{wt} \%$ aqueous solution of PDDA for some time, such as $10 \mathrm{~min}$, and the wafer rinsed with deionized water, then dried with nitrogen. Then, the PDDA-treated wafer is placed horizontally, face down, into a dispersion of purified CNTs in dimethylformamide (DMF) for $100 \mathrm{~min}$, removed, rinsed with DMF, and dried with nitrogen. The CNTterminated film is then dipped into a $1 \mathrm{wt} \%$ aqueous solution of PDDA in $1.0 \mathrm{M} \mathrm{NaCl}$ for 10 min, followed by rinsing with deionized water and drying with nitrogen. The addition of 1.0 $\mathrm{M} \mathrm{NaCl}$ to the PDDA was required for uniform film growth as attempts to form films with only $1 \mathrm{wt} \%$ PDDA resulted in little sequential adsorption. Studies on polyelectrolyte multilayer films have shown that the addition of salt causes a dramatic increase in the amount of polyelectrolyte deposited. Atomic force and scanning electron microscopies indicated that the adsorbed CNTs were mostly in the form of 5-10 nm bundles and that uniform substrate coverage occurred. Absorbance spectrophotometry confirmed that the adsorption technique resulted in uniform film growth.

In most recent reports on CNT/ isotactic polypropylene (iPP) nanocomposites, the melt blending technique has been employed,[106] which provides a very simple preparation method. However, some of the drawbacks associated with melt-compounding methods include high energy cost, risk of filler deterioration during processing, and a generally poor dispersion quality. Solution mixing provides an alternative preparation method; however, it requires the use of organic solvents and is limited to relatively small quantities. To overcome the above defects, a novel latex-based method was developed, by which $\mathrm{CNT} /$ polypropylene films were prepared through the incorporation of CNTs into a polypropylene matrix. In addition to being versatile and environmentally friendly, latex technology allows for the achievement of high dispersion qualities. Moreover, it can be easily extended to any matrix polymer with a latex form. It allows the preparation of highperformance lightweight CNT/iPP films, while overcoming the drawbacks of conventional processing methods.

By solution casting from dilute solutions, interpenetrating networks of entangled CNTs and polystyrene (PS) chains were prepared in thin films.[107] The CNTs were first surface grafted with PS chains to provide good compatibility and steric hindrance against reaggregation of the CNTs in the solution phase. The CNTs dispersed quite well in PStoluene solutions. The dispersion of the nanotubes was uniform, extending globally to form a percolated network, capable of withstanding deformation of more than $25 \%$ without fracture. Experimental data show that micronecking of the fracture precursor of crazing was strongly suppressed, which leads to the enhancement of mechanical properties.

Conjugated macromolecules such as poly( $p$-phenyleneethynylene)s (PPEs) can be used to noncovalently functionalize and solubilize CNTs. Using PPE, the resulting SWNT solubilized 
in chloroform can produce a homogeneous SWNT-polycarbonate (PC) composite solution by mixing with a PC solution.[108] After the solution is cast on a glass dish and dried very slowly, a free-standing film can be peeled from the substrate. The infrared photoresponse in the electrical conductivity of SWNTs is dramatically enhanced by embedding SWNTs in the electrically and thermally insulating polymer matrix.

An insulating polymer surface can be used as a guide for the deposition of two-dimensional networks of CNTs. For example, the CNT solution was cast and dried on the surface of electrospun polyamide 11 (PA11) nanofiber films, which can manufacture transparent and electrically conductive thin films. Multiple deposition cycles lead to increased coverage and conductivity.[109]

Also, by a facile method of spray coating, CNT/silane compound hybrid films at a silane sol concentration of $70 \mathrm{wt} \%$ were achieved. In addition, the wettability of the transparent, conductive films can be varied from superhydrophobicity to superhydrophilicity by varying the chemical functionality of the silane sol. The stable CNT/silane sol solution was prepared based on the intermolecular interactions between the hydroxyl groups of the CNTs and the silanol groups of the silane sol.[110] This CNT-based film may provide a wide range of applications in the development of self-cleaning coatings for optoelectronics, transparent film heating, electrostatic discharging, and electromagnetic interference shielding.

CNTs/PMMA composite films showing anisotropic electrical transport properties can be fabricated using the electric-field-assisted thermal annealing method.[111] Because of the alignment of the SWNT along the electric field direction, the electric-field-assisted thermal annealing of octadecylamine-functionalized SWNT/PMMA films induces an increase in the composite transverse conductivity by several orders of magnitude and a decrease in the lateral conductivity.

\subsection{Conjugated polymer-CNT thin films}

Because of the strong $\pi-\pi$ interactions, CNTs are easily dispersed into conjugated polymer solutions. So, for the synthesis of conjugated polymer-CNT thin films, the solution-casting method is very applicable. For example, CNT/polythiophene (P3HT) films can be fabricated using a very simple spin-casting technique. The resulting film is regarded as a highperformance chemical sensor.[112]

Among the conjugated polymers, P3HT has attracted much research interest because the high-molecular-weight P3HT forms very stable dispersions. Based on solution casting, a free-standing, light-pink-colored SWCNT/P3HT film is readily released from the glass slide substrate as soon as it is dipped into deionized water. This free-standing film exhibits good electrical properties, comparable with commercial ITO and PEDOT/PSS systems.

The highly aromatic pyrenyl group is known to interact strongly with the basal plane of graphite via $\pi$-stacking, and also strongly interacts with the sidewalls of SWNTs in a similar manner.[113] Based on this interaction, a CNT film was prepared containing a dye, $N-(1-$ pyrenyl)maleimide (PM), and a functionalized SWNT-conjugated polymer, poly(3octylthiophene) (P3OT), from drop or spin casting. The photoresponse was improved by functionalizing the SWNT with dye molecules. The short-circuit current was found to increase by more than an order of magnitude compared with the SWNT-polymer diode without dye. The increase in short-circuit current is probably because of efficient transfer of holes by dye molecules to P3OT at the dye/polymer interface and the rapid transfer of the generated electrons to the SWNTs at the dye/nanotube interface. 
Studies have shown that addition of small amounts of conjugated polymer to nanotube dispersions enables straightforward fabrication of uniform network films by spin coating. After treatment with thionyl chloride, electrodes have significantly decreased sheet resistances. For example, adding a minimal quantity of P3AT or poly[2-methoxy-5-(2ethylhexyloxy)-1,4-phenylene vinylene] (MEH-PPV) to CNT dispersions is sufficient to disperse the nanotubes for spin coating onto glass or PET substrates, to fabricate a transparent conducting film with a uniform CNT network. The technique provides an easy, reliable, scalable, plastics-compatible method for fabricating flexible transparent electrodes directly from solution onto the substrate of interest.[114]

Polybenzimidazole (PBI) has been shown individually to dissolve/disperse SWNTs in $N, N$ dimethylacetamide (DMAc).[115] By casting these dispersions, SWNTs/PBI composite films were successfully fabricated on substrates without macroscopic aggregation. The addition of SWNTs to PBI does not reduce the thermal stability of the matrix film, and the mechanical properties of the PBI film were reinforced by ca. 50\% with only $0.06 \mathrm{wt} \%$ addition of the SWNTs because of the $\pi-\pi$ interaction between the PBI and the sidewalls of the SWNTs.

In the case of CNTs, the hydrophobic part of the poly(4-vinylpyridine) (PVP) chain can be bound to the CNTs' surface via hydrophobic and other intermolecular interactions (e.g., $\pi$ stacking interactions) to form a stable CNT/PVP composite. By using this feature, a $\mathrm{CNT} / \mathrm{PVP} / \mathrm{PB}$ composite film was synthesized by casting CNTs wrapped with PVP on gold electrodes followed by electrochemical deposition of $\mathrm{PB}$, which was shown to act as an amperometric biosensor, because of the remarkable synergistic effect of the CNTs and PB.[116]

Electrochemical codeposition is another concise chemical method to prepare conjugated polymer-CNT thin films based on their respective electrochemical properties. By this method, homogeneous nanocomposites of CNT-polyaniline (PANI) resulted.[117] For this, the CNTs should be functionalized in advance via polymerizable groups. This also helped to disperse the nanotubes in aniline. The combination of PANI with CNTs would offer an attractive composite support material for an electrocatalyst to enhance its activity and stability based on morphological modification or electronic interaction between two components.

\subsection{Pure carbon thin films from fullerene and CNT}

$\mathrm{C}_{60}$ and $\mathrm{CNTs}$, as novel all-carbon $\pi$-electron systems, have increasingly invited exploration for preparing their composite films from both fundamental and practical points of view. It is known that clusters of $\mathrm{C}_{60}$ [118-120] and carbon nanostructures [121] can be deposited electrophoretically onto electrodes to form a film. In this manner, the clusters of $\mathrm{C}_{60}$ and SWNT were attached to electrodes such as $\mathrm{FTO} / \mathrm{SnO}_{2}$ (FTO represents F-doped tin oxide) to form a film of $\left(\mathrm{C}_{60}+\mathrm{SWNT}\right)_{m}$. Under application of a high d.c. electric field (200 V for $\left.120 \mathrm{~s}\right)$, the clusters of $\mathrm{C}_{60}$ and functionalized SWNT move toward the positively charged electrode. With increasing time of deposition, the FTO/ $\mathrm{SnO}_{2}$ electrode turns brown for $\left(\mathrm{C}_{60}\right)_{m}$ and $\left(\mathrm{C}_{60}\right.$ + SWNT $)_{m}$, or black for $(\mathrm{SWNT})_{m}$. The time to reach a maximum absorbance increases in the order (f-SWNT $)_{m}<\left(\mathrm{C}_{60}+\mathrm{f}-\mathrm{SWNT}\right)_{m}<\left(\mathrm{C}_{60}\right)_{m}$, because of the faster deposition of (f-SWNT) $)_{m}$ than of $\left(\mathrm{C}_{60}\right)_{m}$. The difference in the mobilities of the clusters leads to inhomogeneous structures in the deposited composite film of $\mathrm{C}_{60}$ and f-SWNT. The composite film exhibited an incident photon-to-photocurrent efficiency as high as $18 \%$ at $1400 \mathrm{~nm}$ under an applied potential of $0.05 \mathrm{~V}$ vs. SCE. The photocurrent generation efficiency is the highest value 
among CNT-based photoelectrochemical devices in which CNTs are deposited onto electrodes electrophoretically, electrostatically, or covalently.[122]

For the preparation of $\mathrm{C}_{60}$ and CNTs, one of the key challenges is to overcome the high aggregation tendency of these nanoscale carbon spheres and fibers. A $\mathrm{C}_{60}-\mathrm{CNT}$ composite film was created by CV.[123] Briefly, purified MWNTs and $\mathrm{C}_{60}\left(\mathrm{MWNTs} / \mathrm{C}_{60}=2: 1\right)$ with a total amount of about $1 \mathrm{mg}$ were dispersed in $10 \mathrm{~mL}$ toluene in an ultrasound bath for 30 min to give a $0.1 \mathrm{mg} \mathrm{mL}^{-1}$ suspension. A volume of $15 \mathrm{~mL}$ of the suspension was cast directly onto a glassy carbon (GC) electrode surface and the solvent was allowed to evaporate at room temperature. This $\mathrm{C}_{60}-\mathrm{MWNT}$ film electrode was subjected to potential scanning in acetonitrile solution containing $0.1 \mathrm{M}$ tetrabutylammonium hexafluorophosphate $\left(\mathrm{TBAPF}_{6}\right.$ ) between 0.0 and $-2.0 \mathrm{~V}$ (vs. $\mathrm{Ag} / \mathrm{AgCl}$ ). The resultant $\mathrm{C}_{60}-$ MWNT film electrode was then washed with acetonitrile several times to remove the electrolytes, and then dried at room temperature. The uniform composite films show reversible redox behavior, which is similar to that of $\mathrm{C}_{60}$ dissolved in organic solution but is very different from those of either $\mathrm{C}_{60}$ films, $\mathrm{CNT}$ films, or peapod films. It is presumed that these novel properties come from the covalent anchorage of $\mathrm{C}_{60}$ to the CNTs in a uniform fashion.

Using the above method, hemoglobin $(\mathrm{Hb})$ was embedded into $\mathrm{C}_{60}-\mathrm{CNT}$ film.[124] Experimental results demonstrated that $\mathrm{C}_{60}-\mathrm{CNT}$ films can facilitate the direct electron transfer of $\mathrm{Hb}$ much more effectively than bare $\mathrm{CNT}$ films. This is attributed to the faster electron-transfer kinetics on the $\mathrm{C}_{60}-\mathrm{CNT}$ film from the roles of electron mediator and protein docking site played by $\mathrm{C}_{60}$, which is finely dispersed on the MWNT surfaces. In this way, $\mathrm{Hb}$ can transfer electrons to and from the electrode more easily through $\mathrm{C}_{60}$ in the $\mathrm{C}_{60}-$ $\mathrm{CNT}$ nanocomposite film. The obtained $\mathrm{Hb} / \mathrm{C}_{60}-\mathrm{MWNT}$ film was shown to act as a new biochemical sensor for the reduction of $\mathrm{O}_{2}$.

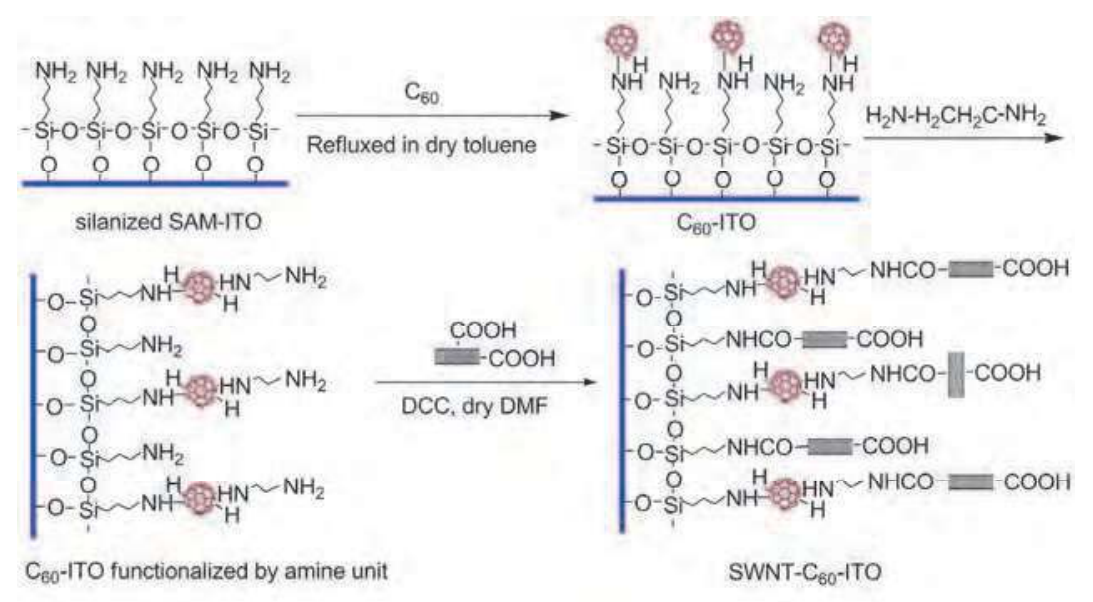

Scheme 1. Schematic illustration of the preparation route to $\mathrm{C}_{60}-\mathrm{SWNT}$ ultrathin film grafted onto ITO step-by-step. Reproduced with permission from Ref. [125]. Copyright 2009 American Chemical Society. 


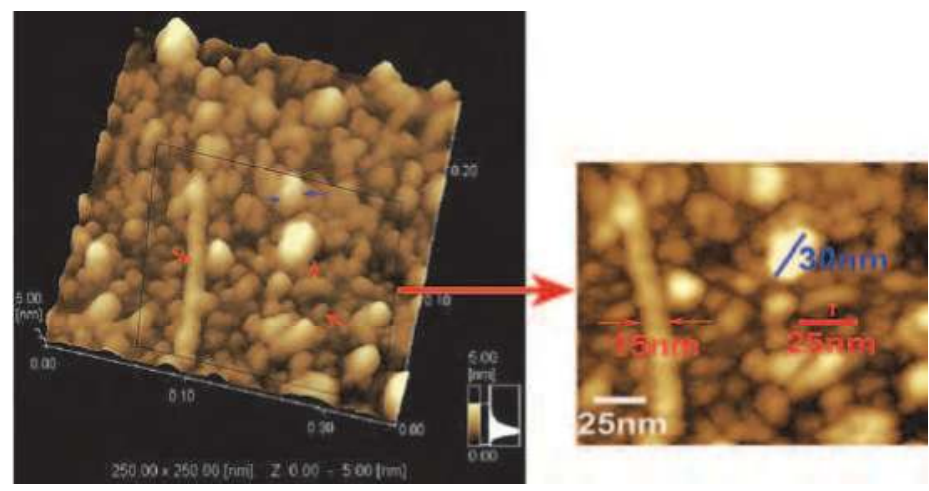

Fig. 8. Typical AFM images of SWNT-C $60-I T O$. Reproduced with permission from Ref. [125]. Copyright 2009 American Chemical Society.

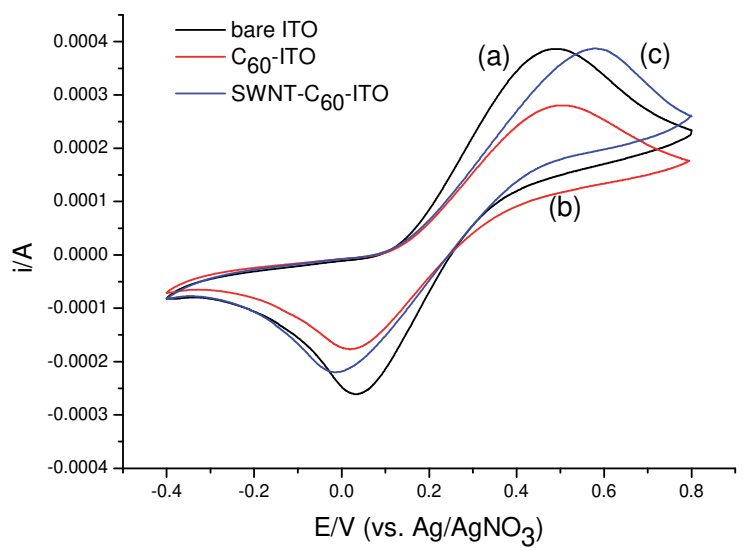

Fig. 9. Cyclic voltammograms of bare ITO (a), $\mathrm{C}_{60}-\mathrm{ITO}$ (b), and SWNT-C $60-\mathrm{ITO}$ (c) in acetonitrile with $3 \mathrm{mM}$ ferrocene as an internal probe. Reproduced with permission from Ref. [125]. Copyright 2009 American Chemical Society.

By using a step-by-step method, we prepared homogeneous ultrathin films composed of [60]-fullerene $\left(\mathrm{C}_{60}\right)$ and SWNTs, grafted to the functional surface of an alkylsilane SAM on an ITO substrate with an ITO- $\mathrm{C}_{60}-\mathrm{SWNT}$ sequence using amine addition across a double bond in $\mathrm{C}_{60}$ followed by amidation coupling with acid-functionalized SWNTs (Scheme 1).[125] AFM images of the resulting composite film showed two-component ball-tube microstructures with high-density coverage, where $\mathrm{C}_{60}$ was homogeneously distributed in the SWNT forest (Figure 8). The attachment of SWNTs to the residual amine units in the SAM on the ITO substrate (SAM-ITO) as well as on the $\mathrm{C}_{60}$ sphere results in the $\mathrm{C}_{60}$ molecules in the aggregated clusters being more separately dispersed, which forms a densely packed composite film as a result of the $\pi-\pi$ interaction between the $\mathrm{C}_{60}$ buckyballs and the SWNT walls. It was found using ferrocene as an internal redox probe that the oxidative and reductive processes at the film-solution surface were effectively retarded because of obstruction from the densely packed film and the electronic effect of SWNT and 
$\mathrm{C}_{60}$ (Figure 9). In addition, the electrochemical properties of $\mathrm{C}_{60}$ on SAM-ITO plates observed by CV were significantly modified by chemical anchorage using SWNTs (Figure 10). X-ray photoelectron spectroscopy (XPS) analysis also indicated the successful grafting of $\mathrm{C}_{60}$ and SWNT. The XPS chemical shift of the binding energy showed the presence of electronic interactions between $\mathrm{C}_{60}$, SWNT, and ITO components. Such a uniformly distributed $\mathrm{C}_{60}-\mathrm{SWNT}$ film may be useful for future research in electrochemical and photoactive nanodevices.
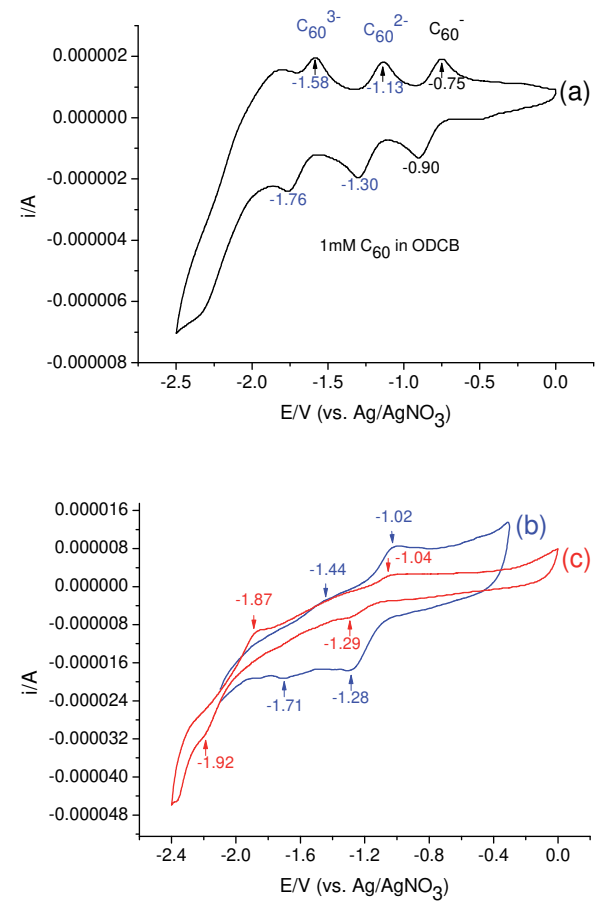

Fig. 10. Cyclic voltammograms of (a) 1 mM C60/ODCB solution, (b) $\mathrm{C}_{60}-\mathrm{ITO}$, and (c) SWNT$\mathrm{C}_{60}-\mathrm{ITO}$ in $\mathrm{CH}_{3} \mathrm{CN}$. Reproduced with permission from Ref. [125]. Copyright 2009 American Chemical Society.

\section{Properties}

\subsection{Mechanical strength}

Similar to other engineering materials, the strength of macroscale SWNTs in film is dominated by the stress-transfer mechanism rather than the strength of individual CNTs. A 200-nm-thick film exhibits high tensile strength and good toughness. The tensile strength is $360 \mathrm{MPa}$, which is 30 and 10 times higher than typical bulky paper and sheets from oleum,[126] respectively; the density-normalized stress is $280 \mathrm{MPa} /\left(\mathrm{g} / \mathrm{cm}^{3}\right)$. The Young's modulus is about $5 \mathrm{GPa}$. Compared with the theoretical strength of individual SWNTs (37 $\mathrm{GPa})$, the film strength is two orders lower. As is known, despite the high stiffness and 
strength of individual SWNTs, slippage between nanotube surfaces reduces the prospect of using SWNT bundles as reinforcing material in composites.[127,128] To resolve the "slipping problem", several routes have been proposed, such as reducing the bundles' diameters, bridging adjacent tubes by electron-beam irradiation,[129] or prolonging the contact length between tubes;[130] however, none of them have proved feasible at the macroscale.

By using a homemade microextensiometer set inside the SEM chamber, the in situ morphologies of CNT can be observed when the films are extended. The changes in morphology show that when the strain is far below the strain-to-failure, the "meshes" in the networks extend continuously and homogeneously. With increasing strain, stress concentrations occur at weak points and become more and more severe. Close to the strainto-failure, extension mainly occurs at the breaking point, where meshes are destroyed and the remaining tubes completely align. Once the breaking point develops, the concentrated stress will split the films rapidly. The maximum extension ratio of the basic unit is $33 \%$, far higher than the typical strain-to-failure of films (10\%). From the above, the mechanical property of the macroscopic films is dominated by the basic units, meshes, rather than straight bundles, and the load is homogeneously transferred to the whole film through shared bundles of adjacent meshes.

Mechanical characterization of the CNT films was provided by nanoindentation tests. Similar load-depth data were obtained for loads of $10 \mathrm{mN}$ and $1 \mathrm{mN}$. The values of Young's modulus vary significantly, from 7.7 to $77.7 \mathrm{GPa}$ for the $1 \mathrm{mN}$ load, and from 70.0 to 157.8 GPa for the $10 \mathrm{mN}$ load. Hardness varies from 0.15 to $1.19 \mathrm{GPa}$ and from 0.5 to $2.12 \mathrm{GPa}$, respectively. Probably, the broad ranges come from a network of rods that are very rigid in tension but flexible in bending,[131] and are probed at the same length scale as the network features.

It is also worth noting that the mechanical properties of individual nanoscale objects are difficult to measure directly; indeed, nanotubes are particularly heterogeneous, both in dimensions and internal perfection, giving rise to significant variation from one nanotube to another. In fact, the response is controlled by a small number of nanotubes, and is susceptible to local variations in microstructure.

\subsection{Thermal response}

As a transparent conducting coating, thin films of CNTs have outstanding performance as a thermal interface layer for heat dissipation in high-density electronic packaging.[132] Because CNT film is composed of a network of individual CNTs and CNT bundles, the thermal and electrical resistances are dominated by the intertube junctions,[133-136] which depend strongly on chemical modification of the SWNTs and the film-preparation technology. In general, the relative contribution of the electron and phonon components of the thermal conductivity can be evaluated on the basis of the Lorenz number, $L=\kappa / \sigma T$. The Lorenz number for the purified SWNT film is close to $7 \times 10^{-6} \mathrm{~W} \Omega / \mathrm{K}^{2}$ at temperatures between 50 and $300 \mathrm{~K}$, which corresponds to a ratio of the electron-to-phonon contribution to the thermal conductivity of 1 to 100 , which is further decreased to 1 to 10000 in the case of the as prepared SWNT network.

The electrical resistance at the junction of two metallic SWNTs was found to be $200 \mathrm{k} \Omega$, contact of two semiconducting SWNTs showed a junction resistance of $500 \mathrm{k} \Omega$, while contact of metallic and semiconducting SWNTs provided the most resistive junction $(>10$ 
$\mathrm{M} \Omega$ ) because of the Schottky barrier.[36] The heat conductance at the intertube junctions, $G_{\mathrm{J}}$, was evaluated theoretically not to exceed $10^{-9} \mathrm{~W} / \mathrm{K} .[137,138]$ The average junction electrical resistance can be evaluated at about $R_{\mathrm{J}}=10^{6} \Omega$. Experimental data show a Lorenz number for individual cross-junctions at $300 \mathrm{~K}$ of $L_{\mathrm{J}}=3 \times 10^{-6} \mathrm{~W} \Omega / \mathrm{K}^{2}$, close to the value obtained for purified SWNT film and two orders of magnitude higher than the pure electronic value, $L_{\mathrm{e}}=2.4453 \times 10^{-8} \mathrm{~W} \Omega / \mathrm{K}^{2}$. That is to say, heat transport across the intertube junction is dominated by the phonon component. Both electrical and thermal transport in SWNT networks are dominated by intertube junctions. It should be noted that, in the case of an SWNT network embedded in a polymer matrix, stronger suppression of both electrical conductivity and larger Lorenz numbers $\left(10^{-2} \mathrm{~W} \Omega / \mathrm{K}^{2}\right)$ were observed.

\subsection{Electrical conductivity}

Although the axial conductivity of an SWNT rope can reach 10000-30000 S/cm, conductivity in films or networks is usually one or two orders lower. For CNT films, sheet resistance is the result of three distinct contributions. The first is from the CNTs themselves. Many inherent factors have an effect on the electronic properties of nanotubes, including diameter, chirality, defect, curvature, and local environment.[139] As a result, their inhomogeneous distribution complicates the conductivity of the films. The second component is the existence of some barriers at intertube junctions.[140] Electron transport via the hopping mechanism through the intertube junctions is predominant in the conductivity of CNT films. Finally, the additional resistances introduced during the fabrication process of CNT films also contribute to sheet resistance, such as residual surfactant.

For transparent conductive thin films fabricated through a procedure based on the filtration method, the sheet resistance has varying degrees of improvement after the multistep purification process. After removing the mixed cellulose ester (MCE) filtration membrane, L-SWNT films ("laser" nanotubes) present the lowest sheet resistances, while those of $\mathrm{H}$ SWNT ("HiPCO" nanotubes) films show the highest. The sheet resistance of A-SWNT ("arcdischarge" nanotubes) films is close to that of L-SWNT films, because of the same range of diameters and lengths. The high resistance of H-SWNT films arises from their much smaller diameter and length compared with those of L-SWNTs or A-SWNTs.[141]

The conductivity of the SWNT films features a sharp jump of several orders of magnitude, attributed to a typical electrical phenomenon dealing with the formation of a network of conductive particles in terms of percolation theory.[142] Percolation is a statistical geometric theory that has established the universality of the exponents in the power law dependence of geometrical parameters. In plain terms, for SWNT films just above the percolation threshold, sheet resistance reduces dramatically with the increase in film thickness, while in the region far from the threshold, sheet resistance decreases inversely with film thickness, as expected for constant conductivity.

After washing off the surfactants, the electrical conductivity of the SWNT film coatings was improved further by treatment with various acids. Upon treatment with acids, Geng et al.[143] observed a fivefold increase in the electrical conductivity of SWNT thin films that had been made using a surfactant-based dispersion and had been washed to remove residual surfactant. They proposed that the acid removed residual surfactant molecules adsorbed on the surface of the nanotubes, leading to better contact between the nanotubes, densification of the films, and improvement in overall electrical conduction properties. 


\subsection{Electrochemical properties}

CNTs have a high electrochemically accessible area of porous tubes, as well as good electronic conductance and good electrocatalytic activity, which give CNTs enormous potential as components of nanoscale electronic devices and biosensors, particularly for the CNT films fabricated on electrodes.

A potential application of the electrochemical active CNT film is the electrocatalytic activity toward $\mathrm{O}_{2}$ reduction in alkaline media.[144] These properties essentially suggest that the CNTs are a potential candidate for development of effective, low-cost, and environmentally benign nonplatinum alkaline air electrodes for energy conversions. For example, the CNT multilayer films on GC electrodes, developed by the LBL method, based on the electrostatic interaction between positively charged poly(diallyldimethylammonium chloride) (PDDA) and negatively charged and shortened MWNTs, show remarkable electrocatalytic activity for $\mathrm{O}_{2}$ reduction in alkaline media.

Because the diameters and carrier densities of SWNTs are comparable to the sizes and surface-charge densities of biomacromolecules, SWNTs can serve as ultrasensitive transducers in biosensors based on chem-resistor or transistor structures.[145,146] A more generalized and reliable approach to achieve specific detection involves direct chemical functionalization of the SWNTs. Noncovalent approaches are generally preferred as they do not degrade the intrinsic electrical properties of the SWNTs.[147]

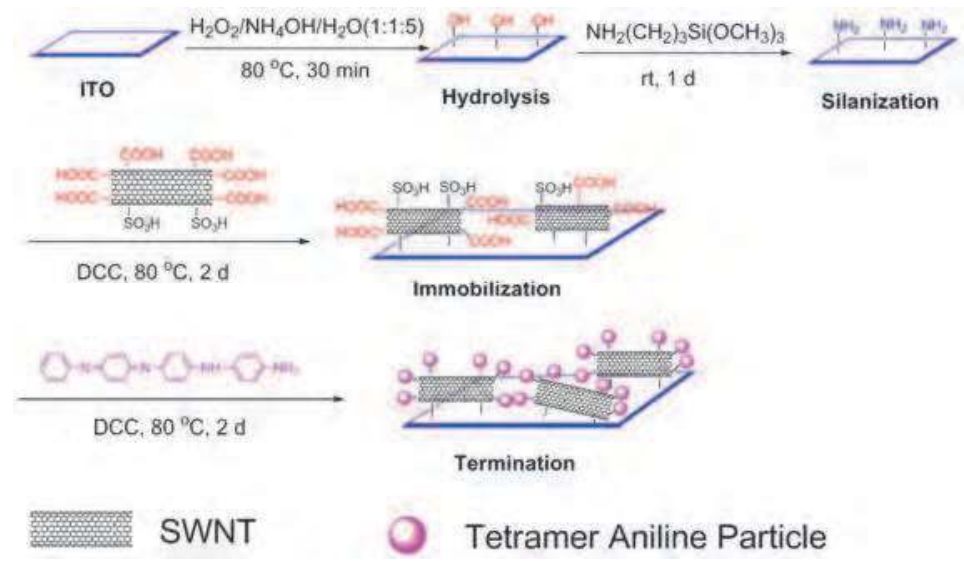

Scheme 2. Schematic illustration of the preparation route for attaching a functionalized SWNT layer onto an ITO endcapped by a tetramer aniline group. Reproduced with permission from Ref. [149]. Copyright 2009 Chemical Society of Japan.

SWNTs chemically assembled on functional monolayer-coated Au substrates show quasireversible $\mathrm{CV}$ features, indicating that, although directly linked to the insulating monolayer, the assembled SWNTs allow electron exchange between the gold electrode and the redox couple in solution. Electron tunneling between assembled SWNTs and the underlying gold substrate is involved in the charge-transfer process. The insulating monolayer between the gold substrate and the SWNTs acts as an electron-tunneling barrier. The high electron-transfer efficiency for the electrodes was ascribed to the large $\pi$ conjugated system within SWNTs, which enables SWNTs to accept or donate electrons, and to the efficient through-bond tunneling between the gold electrode and SWNTs, which can be described by the apparent tunneling resistance.[148] 
In our group, SAMs of SWNTs covalently attached to a (3-aminopropyl)trimethoxysilanemodified ITO surface (SAM-ITO) were prepared from a soluble SWNT, which was safely obtained via a two-step process assisted by microwave irradiation (Scheme 2).[149]

It has been reported that SWNTs can be quickly functionalized under the assistance of UV or microwave irradiation,[150,151] plasma or ozone treatment.[152,153] A two-step method was developed to prepare soluble functionalized SWNTs assisted by a microwave oven in our group. Compared with the preparation under higher pressure,[151] the two-step approach allowed for a safer and easier operation. The FT-IR data of the soluble functionalized SWNTs showed a strong stretching mode of the $-\mathrm{COOH}$ groups from the SWNT backbone, and a weaker peak attributed to the asymmetric $\mathrm{SO}_{2}$ stretching mode of the acid sulfonate $\left(-\mathrm{SO}_{2} \mathrm{OH}\right)$ group, which implied that most of the functionalized carbon atoms on the SWNT backbone were carboxylated, with the remainder being sulfonated.

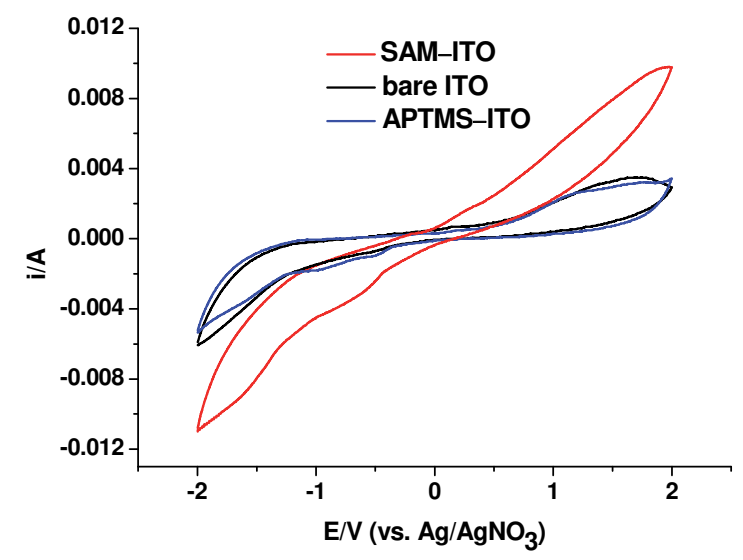

Fig. 11. CV traces of bare ITO, (3-aminopropyl)trimethoxysilane-modified ITO (APTMS-ITO) and SWNT-functionalized ITO (SAM-ITO) in $\mathrm{CH}_{3} \mathrm{CN}$ with $0.1 \mathrm{M}$ tetrabutylammonium perchlorate (TBAP) as the supporting electrolyte. Scan rate $=0.05 \mathrm{~V} / \mathrm{s}$. Reproduced with permission from Ref. [149]. Copyright 2009 Chemical Society of Japan.

Cyclic voltammograms of CNT thin films self-assembled on ITO-coated glass by the coupling reaction of the amine groups with the carboxyl groups from the soluble SWNTs showed a higher capacitor charging current than in the bare ITO plates, as shown by the curves in Figure 11, which was attributed to the presence of SWNTs, resulting in an increase in the active electrochemical components.

To evaluate the stability in water of the water-soluble SWNTs layer, the SAM-ITO electrode was successively scanned for five cycles from -0.3 to $0.9 \mathrm{~V}$ at a rate of $0.05 \mathrm{~V} / \mathrm{s}$ in a $1.0 \mathrm{M}$ $\mathrm{H}_{2} \mathrm{SO}_{4}$ aqueous solution. Surprisingly, the CV data of the SAM-ITO electrodes (Figure 12a) demonstrated that oxidation occurred at 0.42 and $0.56 \mathrm{~V}$ and reduction occurred at $0.24 \mathrm{~V}$, which showed a lower stability than in an organic TBAP / acetonitrile solution. Similar electrochemical reactions in aqueous solution, associated with surface oxygen complexes and increasing defect densities of the carbon nanotubes, have been reported previously, and the redox peaks have been assigned recently.[154,155] This is reasonable, considering that these peaks were also assigned to redox reactions involving defects and sidewalls of soluble functionalized SWNTs. 


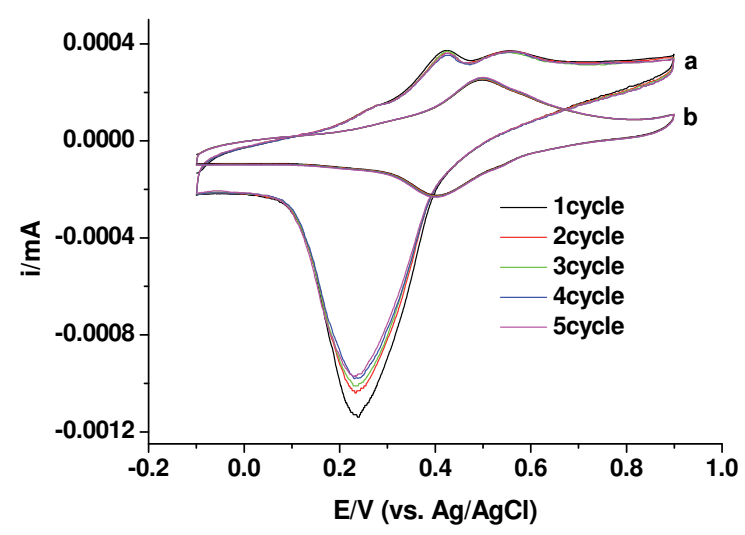

Fig. 12. CV traces of (a) SWNT SAM-ITO and (b) SWNT SAM-ITO endcapped by tetramer aniline groups in an aqueous $1.0 \mathrm{M} \mathrm{H}_{2} \mathrm{SO}_{4}$ solution. Scan rate $=0.05 \mathrm{~V} / \mathrm{s}$. Reproduced with permission from Ref. [149]. Copyright 2009 Chemical Society of Japan.

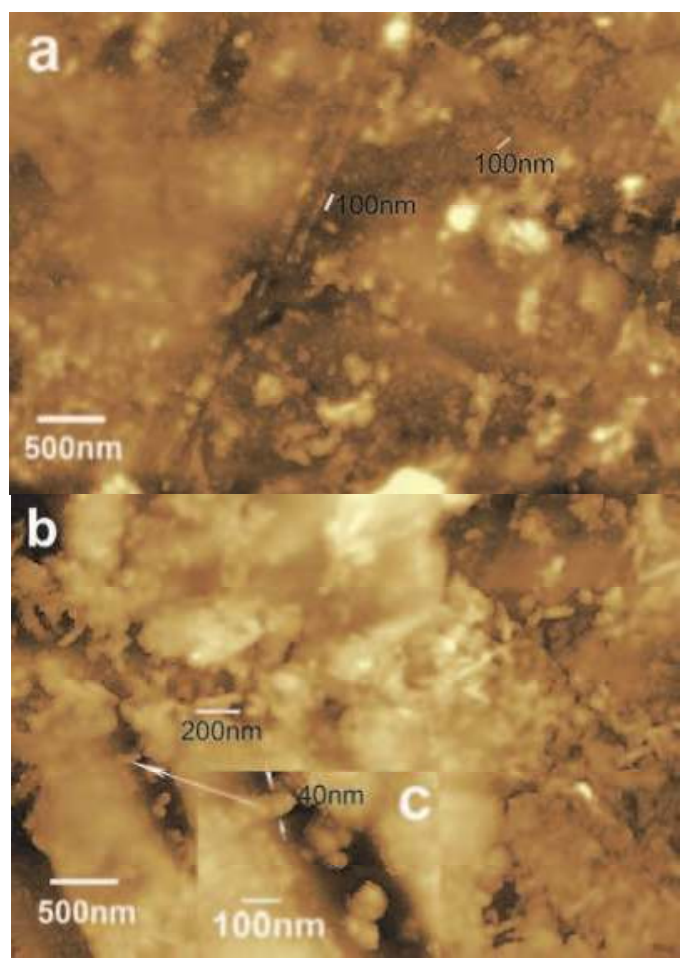

Fig. 13. Tapping mode AFM images of (a) SAM-ITO and (b) tetramer aniline-terminated ITO surface. Insert (c) shows the high-resolution image of an SWNT surface after being endcapped by tetramer aniline. Reproduced with permission from Ref. [149]. Copyright 2009 Chemical Society of Japan. 

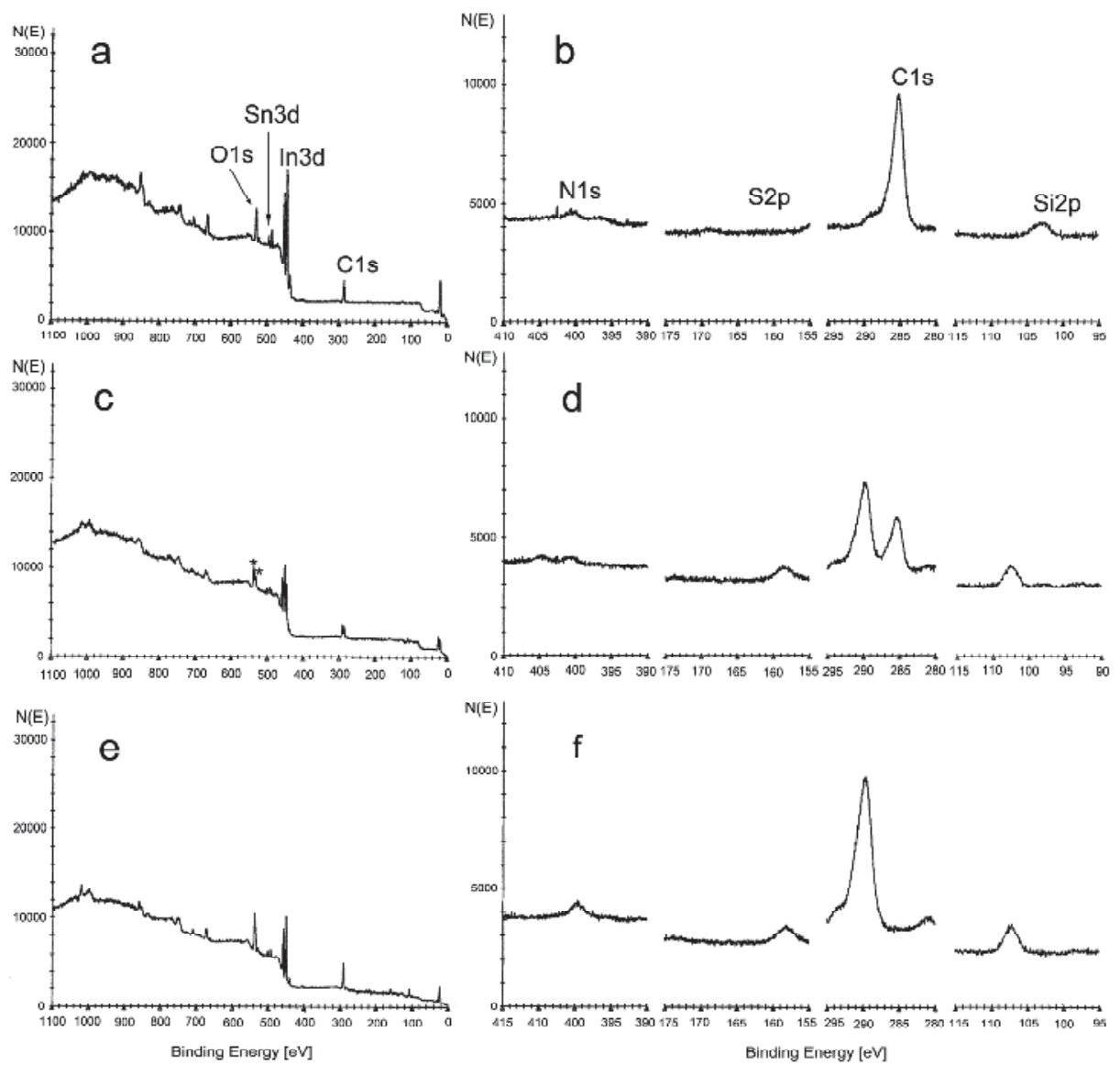

Fig. 14. The XPS wide-scan spectra of: (a) pristine ITO, (c) SAM-ITO, (e) tetramer anilineterminated ITO surface, and (b), (d), and (f) their corresponding high resolution N 1s, S 2p, C 1s, and Si 2p spectra, respectively. Reproduced with permission from Ref. [149].

Copyright 2009 Chemical Society of Japan.

However, the CV data recorded for tetramer aniline end-capped SAM-ITO (Figure 12b) showed two reversible redox couples occurring at 0.50 and $0.40 \mathrm{~V}$ under the same conditions, which were assigned to the oxidation and reduction of the tetramer aniline between the leucoemeraldine and emeraldine oxidation states. Moreover, this was very reproducible, indicating that the stability of the SAM-ITO was improved after being endcapped by the tetramer aniline molecules.

From the AFM images in Figure 13, the SAM-ITO plate showed a monolayer with tube-like particle topography, implying the successful incorporation of functionalized SWNTs onto the ITO surface. The average length of the functionalized SWNTs is around $100 \mathrm{~nm}$, with average diameter of around $20 \mathrm{~nm}$. The morphology of the obtained SWNT layer was significantly changed after being end-capped using tetramer aniline groups (Figure 13b), 
which showed a rougher SWNT surface compared with that of SWNT-ITO (see arrow label in Figure 13c). From the AFM image shown in Figure 13b, the average length of the tetramer aniline terminated SWNTs is around $200 \mathrm{~nm}$ with an average diameter of around $40 \mathrm{~nm}$, which showed a significant increase compared with that of the pure SWNT layer, because of the presence of a tetramer aniline particle layer linked with functionalized SWNTs by chemical bonds.

The XPS analysis showed the oxygen-containing defects on functionalized SWNT walls were covered and protected by tetramer aniline groups after end-capping, as shown in Figure 14. In addition to the intense and sharp features of the In $3 d, S n 3 d$, and O 1s peaks, the spectrum of the bare ITO plate exhibited weak C 1s and Si $2 p$ peaks, which correspond to minor surface carbon contamination and the silicon from the glass, respectively (Figures 14a and 14b).[156] After attachment of the soluble functionalized SWNT, the peak intensity of the In $3 d$, Sn 3d, and O 1s peaks decreased, and the Si $2 p$ peaks increased, because of the linked APTMS agent between the ITO layer and the functionalized SWNT (Figures 14c and $14 \mathrm{~d})$. In addition, the observed $\mathrm{S} 2 \mathrm{p}$ feature showed the presence of acid sulfonate $\left(-\mathrm{SO}_{2} \mathrm{OH}\right)$ groups on the functionalized SWNTs. Aside from the C-C/ C-H peak at $285.3 \mathrm{eV}$, an additional photoemission representing the higher binding energy bands indicated the presence of carbon atoms bonded to other functional groups. The binding energy peak occurring at $290 \mathrm{eV}$ was attributed to $\mathrm{C}=\mathrm{O}$ and $\mathrm{O}-\mathrm{C}=\mathrm{O}$ groups from the functionalized SWNTs. The two-peak feature of $\mathrm{O} 1$ s peaks (denoted by asterisks in Figure 14c) shown in the wide-scan spectra compared to that of the bare ITO plate, also offers evidence for different chemical bonded states that correspond to $\mathrm{COOH}$ groups on the functionalized SWNT surface. However, after end-capping the residual carboxyl acid groups by the tetramer aniline terminated by amine groups, the intensity of the $\mathrm{C} 1 \mathrm{~s}$ and $\mathrm{O} 1 \mathrm{~s}$ features in the higher binding energy bands was significantly decreased to form a shoulder peak, as shown in Figures 14e and 14f. In addition, from the corresponding peak areas, the atomic content of the $\mathrm{C} 1 \mathrm{~s}$ and $\mathrm{N}$ 1s peaks was enhanced compared to that of the In $3 \mathrm{~d}$ or $\mathrm{Sn} 3 \mathrm{~d}$ peaks. This is reasonable, considering that the enriched particle assembled by endterminated tetramer aniline molecules tightly covered the sidewalls of the soluble functionalized SWNT via $\pi-\pi$ interactions, where only the photoemission of the $C 1 \mathrm{~s}$ and N 1s peaks assigned to the tetramer aniline backbone was detected. This results in an increase of the $\mathrm{N}$ 1s and $\mathrm{C}$ 1s peaks in the lower binding energy bands, and a decrease in the $\mathrm{C} 1 \mathrm{~s}$ and $\mathrm{O} 1 \mathrm{~s}$ peaks in the higher binding energy bands.

As discussed above, the conjugate layer, assembled by the end-terminated tetramer aniline molecules, tightly covered the sidewalls of the soluble functionalized SWNTs via covalent bonding and $\pi-\pi$ interactions, together with the doping effect between tetramer aniline and the sulfonic groups on the SWNT surface, which made the SWNT layer more stable in the $\mathrm{CV}$ scans in acidic aqueous solutions. It is expected that this stable electroactive SWNT layer will find a wealth of applications in nanocomposite architectures.

\section{References}

[1] R. H. Baughman, A. A. Zakhidov, W. A. de Heer, Science 2002, 297, 787.

[2] P. M. Ajayan, O. Stephan, C. Colliex, D. Trauth, Science 1994, 265, 1212.

[3] P. Calvert, Nature 1999, 399, 210.

[4] T. X. Liu, I. Y. Phang, L. Shen, S. Y. Chow, W. D. Zhang, Macromolecules 2004, 37, 7214.

[5] P. M. Ajayan, Chem. Rev. 1999, 99, 1787. 
[6] P. Avouris, Acc. Chem. Res. 2002, 35, 1026.

[7] M. Ouyang, J. L. Huang, C. M. Lieber, Acc. Chem. Res. 2002, 35, 1018.

[8] V. N. Popov, Mater. Sci. Eng. R 2004, 43, 61.

[9] Q. Cao, J. A. Rogers, Adv. Mater. 2009, 21, 29

[10] H. J. Dai, Acc. Chem. Res. 2002, 35, 1035.

[11] X. J. Zhou, J. Y. Park, S. M. Huang, J. Liu, P. L. McEuen, Phys. Rev. Lett. 2005, 95, 146805.

[12] C. T. White, T. N. Todorov, Nature 1998, 393, 240.

[13] B. M. Quinn, S. G. Lemay, Adv. Mater. 2006, 18, 855.

[14] Z. Yao, C. L. Kane, C. Dekker, Phys. Rev. Lett. 2000, 84, 2941.

[15] E. Pop, D. Mann, Q. Wang, K. Goodson, H. J. Dai, Nano Lett. 2006, 6, 96.

[16] E. W. Wong, P. E. Sheehan, C. M. Lieber, Science 1997, 277, 1971.

[17] M. Cinke, J. Li, B. Chen, A. Cassell, L. Delzeit, J. Han, M. Meyyappan, Chem. Phys. Lett. 2002, 365, 69.

[18] S. E. Thompson, S. Parthasarathy, Mater. Today 2006, 9, 20.

[19] P. Avouris, Z. H. Chen, V. Perebeinos, Nat. Nanotechnol. 2007, 2, 605.

[20] W. B. Choi, D. S. Chung, J. H. Kang, H. Y. Kim, Y. W. Jin, I. T. Han, Y. H. Lee, J. E. Jung, N. S. Lee, G. S. Park, J. M. Kim, Appl. Phys. Lett. 1999, 75, 3129.

[21] L. Schlapbach, A. Zuttel, Nature 2001, 414, 353.

[22] A. S. Arico, P. Bruce, B. Scrosati, J. M. Tarascon, W. van Schalkwijk, Nat. Mater. 2005, 4, 366.

[23] Z. Liu, M. Winters, M. Holodniy, H. J. Dai, Angew. Chem., Int. Ed. 2007, 46, 2023.

[24] M. Prato, K. Kostarelos, A. Bianco, Acc. Chem. Res. 2008, 41, 60.

[25] M. Freitag, J. C. Tsang, J. Kirtley, A. Carlsen, J. Chen, A. Troeman, H. Hilgenkamp, P. Avouris, Nano Lett. 2006, 6, 1425.

[26] J. Chen, V. Perebeinos, M. Freitag, J. Tsang, Q. Fu, J. Liu, P. Avouris, Science 2005, 310, 1171.

[27] K. Kordas, G. Toth, P. Moilanen, M. Kumpumaki, J. Vahakangas, A. Uusimaki, R. Vajtai, P. M. Ajayan, Appl. Phys. Lett. 2007, 90, 123105.

[28] T. Iwai, Y. Awano, Fujitsu Sci. Tech. J. 2007, 43, 508.

[29] G. F. Close, S. Yasuda, B. Paul, S. Fujita, H. S. P. Wong, Nano Lett. 2008, 8, 706.

[30] S. N. Kim, J. F. Rusling, F. Papadimitrakopoulos, Adv. Mater. 2007, 19, 3214.

[31] P. Avouris, J. Chen, Mater. Today 2006, 9, 46.

[32] J. Appenzeller, Proc. IEEE 2008, 96, 201.

[33] R. H. Reuss, B. R. Chalamala, A. Moussessian, M. G. Kane, A. Kumar, D. C. Zhang, J. A. Rogers, M. Hatalis, D. Temple, G. Moddel, B. J. Eliasson, M. J. Estes, J. Kunze, E. S. Handy, E. S. Harmon, D. B. Salzman, J. M. Woodall, M. A. Alam, J. Y. Murthy, S. C. Jacobsen, M. Olivier, D. Markus, P. M. Campbell, E. Snow, Proc. IEEE 2005, 93, 1239.

[34] J. P. Edgeworth, N. R. Wilson, J. V. Macpherson, Small 2007, 3, 860.

[35] S. Maruyama, R. Kojima, Y. Miyauchi, S. Chiashi, M. Kohno, Chem. Phys. Lett. 2002, 360, 229.

[36] G. Y. Zhang, D. Mann, L. Zhang, A. Javey, Y. M. Li, E. Yenilmez, Q. Wang, J. P. McVittie, Y. Nishi, J. Gibbons, H. J. Dai, Proc. Natl. Acad. Sci. U.S.A. 2005, 102, 16141. 
[37] Y. Murakami, S. Chiashi, Y. Miyauchi, M. H. Hu, M. Ogura, T. Okubo, S. Maruyama, Chem. Phys. Lett. 2004, 385, 298.

[38] Q. Cao, S.-H. Hur, Z.-T. Zhu, Y. Sun, C. Wang, M. A. Meitl, M. Shim, J. A. Rogers, Adv. Mater. 2006, 18, 304.

[39] G. S. Duesberg, A. P. Graham, M. Liebau, R. Seidel, E. Unger, F. Kreupl, W. Hoenlein, Nano Lett. 2003, 3, 257.

[40] Y. M. Li, W. Kim, Y. G. Zhang, M. Rolandi, D. W. Wang, H. J. Dai, J. Phys. Chem. B 2001, 105, 11424.

[41] K. M. Ryu, A. Badmaev, L. Gomez, F. Ishikawa, B. Lei, C. W. Zhou, J. Am. Chem. Soc. 2007, 129, 10104.

[42] B. B. Wang, S. Lee, X. Z. Xu, S. H. Choi, H. Yan, B. Zhang, W. Hao, Appl. Surf. Sci. 2004, 236, 6 .

[43] E. Joselevich, C. M. Lieber, Nano Lett. 2002, 2, 1137.

[44] Y. G. Zhang, A. L. Chang, J. Cao, Q. Wang, W. Kim, Y. M. Li, N. Morris, E. Yenilmez, J. Kong, H. J. Dai, Appl. Phys. Lett. 2001, 79, 3155.

[45] S. M. Huang, M. Woodson, R. Smalley, J. Liu, Nano Lett. 2004, 4, 1025.

[46] S. M. Huang, X. Y. Cai, J. Liu, J. Am. Chem. Soc. 2003, 125, 5636.

[47] Z. Jin, H. B. Chu, J. Y. Wang, J. X. Hong, W. C. Tan, Y. Li, Nano Lett. 2007, 7, 2073.

[48] S. M. Huang, B. Maynor, X. Y. Cai, J. Liu, Adv. Mater. 2003, 15, 1651.

[49] A. Ismach, L. Segev, E. Wachtel, E. Joselevich, Angew. Chem. Int. Ed. 2004, 43, 6140.

[50] A. Ismach, D. Kantorovich, E. Joselevich, J. Am. Chem. Soc. 2005, 127, 11554.

[51] C. Kocabas, S. H. Hur, A. Gaur, M. A. Meitl, M. Shim, J. A. Rogers, Small 2005, 1, 1110.

[52] S. Han, X. L. Liu, C. W. Zhou, J. Am. Chem. Soc. 2005, 127, 5294.

[53] L. Ding, D. N. Yuan, J. Liu, J. Am. Chem. Soc. 2008, 130, 5428.

[54] C. Kocabas, M. Shim, J. A. Rogers, J. Am. Chem. Soc. 2006, 128, 4540.

[55] T. W. Ebbesen, P. M. Ajayan, Nature 1992, 358, 220.

[56] S. Bandow, S. Asaka, Y. Saito, A. M. Rao, L. Grigorian, E. Richter, P. C. Eklund, Phys. Rev. Lett. 1998, 80, 3779.

[57] K. Mukhopadhyay, A. Koshio, T. Sugai, N. Tanaka, H. Shinohara, Z. Konya, J. B. Nagy, Chem. Phys. Lett. 1999, 303, 117.

[58] H. Yokomichi, F. Sakai, M. Ichihara, N. Kishimoto, Thin Solid Films 2001, 395, 253.

[59] L. C. Qin, D. Zhou, A. R. Krauss, D. M. Gruen, Appl. Phys. Lett. 1998, 72, 3437.

[60] G. W. Meng, Y. J. Jung, A. Cao, R. Vajtai, P. M. Ajayan, Proc. Natl. Acad. Sci. U.S.A. $2005,102,7074$.

[61] B. Q. Wei, R. Vajtai, Y. Jung, J. Ward, R. Zhang, G. Ramanath, P. M. Ajayan, Nature 2002, 416, 495.

[62] Y. J. Jung, B. Q. Wei, R. Vajtai, P. M. Ajayan, Nano Lett. 2003, 3, 561.

[63] B. D. Yao, N. Wang, J. Phys. Chem. B 2001, 105, 11395.

[64] Z. F. Ren, Z. P. Huang, J. W. Xu, J. H. Wang, P. Bush, M. P. Siegel, P. N. Provencio, Science 1998, 282, 1105.

[65] K. B. K. Teo, M. Chhowalla, G. A. J. Amaratunga, W. I. Milne, D. G. Hasko, G. Pirio, P. Legagneux, F. Wyczisk, D. Pribat, Appl. Phys. Lett. 2001, 79, 1534.

[66] J. Chen, M. A. Hamon, H. Hu, Y. Chen, A. M. Rao, P. C. Eklund, R. C. Haddon, Science 1998, 282, 95. 
[67] J. Chen, A. M. Rao, S. Lyuksyutov, M. E. Itkis, M. A. Hamon, H. Hu, R. W. Cohn, P. C. Eklund, D. T. Dolbert, R. E. Smalley, R. C. Haddon, J. Phys. Chem. B 2001, 105, 2525.

[68] S. Banerjee, T. Hemraji-Benny, S. S. Wong, Adv. Mater. 2005, 17, 17.

[69] P. J. Boul, J. Liu, E. T. Mickelson, L. M. Ericson, I. W. Chiang, K. A. Smith, D. T. Colbert, R. H. Hauge, J. L. Margrave, R. E. Smalley, Chem. Phys. Lett. 1999, 310, 367.

[70] V. Georgakilas, K. Kordatos, M. Prato, D. M. Guldi, M. Holzinger, A. Hirsch, J. Am. Chem. Soc. 2002, 124, 760.

[71] J. L. Delgado, P. de la Cruz, F. Langa, A. Urbina, J. Casado, N. J. T. Lopez, Chem. Commun. 2004, 1734.

[72] D. Tasis, N. Tagmatarchis, A. Bianco, M. Prato, Chem. Rev. 2006, 106, 1105.

[73] A. R. Boccaccini, J. Cho, J. A. Roether, B. J. C. Thomas, J. E. Minay, M. S. P. Shaffer, Carbon 2006, 44, 3149.

[74] O. O. Van der Biest, L. J. Vandeperre, Annu. Rev. Mater. Sci. 1999, $29,327$.

[75] P. Sarkar, P. S. Nicholson, J. Am. Ceram. Soc. 1996, 79, 1987.

[76] T. V. Sreekumar, T. Liu, S. Kumar, L. M. Ericson, R. H. Hauge, R. E. Smalley, Chem. Mater. 2003, 15, 175.

[77] L. Hu, D. S. Hecht, G. Grüner, Nano Lett. 2004, 4, 2513.

[78] J. U. Park, M. Hardy, S. J. Kang, K. Barton, K. Adair, D. K. Mukhopadhyay, C. Y. Lee, M. S. Strano, A. G. Alleyne, J. G. Georgiadis, P. M. Ferreira, J. A. Rogers, Nat. Mater. 2007, 6, 782.

[79] K. Kordas, T. Mustonen, G. Toth, H. Jantunen, M. Lajunen, C. Soldano, S. Talapatra, S. Kar, R. Vajtai, P. M. Ajayan, Small 2006, 2, 1021.

[80] M. A. Meitl, Y. X. Zhou, A. Gaur, S. Jeon, M. L. Usrey, M. S. Strano, J. A. Rogers, Nano Lett. 2004, 4, 1643.

[81] J. U. Park, M. A. Meitl, S. H. Hur, M. L. Usrey, M. S. Strano, P. J. A. Kenis, J. A. Rogers, Angew. Chem. Int. Ed. 2006, 45, 581.

[82] E. Artukovic, M. Kaempgen, D. S. Hecht, S. Roth, G. Grüner, Nano Lett. 2005, 5, 757.

[83] E. Pop, D. Mann, Q. Wang, K. Goodson, H. J. Dai, Nano Lett. 2006, 6, 96.

[84] M. F. Yu, O. Lourie, M. J. Dyer, K. Moloni, T. F. Kelly, R. S. Ruoff, Science 2000, 287, 637.

[85] Z. W. Pan, S. S. Xie, L. Lu, B. H. Chang, L. F. Sun, W. Y. Zhou, G. Wang, D. L. Zhang, Appl. Phys. Lett. 1999, 74, 3152.

[86] P. Poncharal, Z. L. Wang, D. Ugarte, W. A. de Heer, Science 1999, 283, 1513.

[87] G. Decher, Science 1997, 277, 1232.

[88] S. W. Lee, B. S. Kim, S. Chen, Y. Shao-Horn, P. T. Hammond, J. Am. Chem. Soc. 2009, $131,671$.

[89] Z. Liu, Z. Shen, T. Zhu, S. Hou, L. Ying, Z. Shi, Z. Gu, Langmuir 2000, 16, 3569.

[90] Z. Chen, Y. Yang, Z. Wu, G. Luo, L. Xie, Z. Liu, S. Ma, W. Guo, J. Phys. Chem. B 2005, 109, 5473.

[91] H. B. Yildiz, R. Tel-Vered, I. Willner, Adv. Funct. Mater. 2008, 18, 3497.

[92] Z. C. Wu, Z. H. Chen, X. Du, J. M. Logan, J. Sippel, M. Nikolou, K. Kamaras, J. R. Reynolds, D. B. Tanner, A. F. Hebard, A. G. Rinzler, Science 2004, 305, 1273.

[93] N. A. Kotov, MRS Bull. 2001, 26, 992.

[94] G. Decher, J. D. Hong, Makromol. Chem. Macromol. Symp. 1991, 46, 321.

[95] G. Decher, J. D. Hong, J. Schmitt, Thin Solid Films 1992, 210, 831. 
[96] W. B. Stockton, M. F. Rubner, Macromolecules 1997, 30, 2717.

[97] L. Y. Wang, Z. Q. Wang, X. Zhang, J. C. Shen, L. F. Chi, H. Fuchs, Macromol. Rapid Commun. 1997, 18, 509.

[98] Y. Shimazaki, M. Mitsuishi, S. Ito, M. Yamamoto, Langmuir 1997, 13, 1385.

[99] J. K. Mwaura, D. L. Thomsen, T. Phely-Bobin, M. Taher, S. Theodoropulos, F. Papadimitrakopoulos, J. Am. Chem. Soc. 2000, 122, 2647.

[100] A. A. Mamedov, N. A. Kotov, M. Prato, D. M. Guldi, J. P. Wicksted, A. Hirsch, Nature Mater. 2002, 1, 190.

[101] J. H. Rouse, P. T. Lillehei, Nano Lett. 2003, 3, 59.

[102] S. H. Qin, D. Q. Qin, W. T. Ford, J. E. Herrera, D. E. Resasco, Macromolecules 2004, 37, 9963.

[103] S. H. Qin, D. Q. Qin, W. T. Ford, J. E. Herrera, D. E. Resasco, S. M. Bachilo, R. B. Weisman, Macromolecules 2004, 37, 3965.

[104] L. M. Clayton, A. K. Sikder, A. Kumar, M. Cinke, M. Meyyappan, T. G. Gerasimov, J. P. Harmon, Adv. Funct. Mater. 2005, 15, 101.

[105] J. H. Rouse, P. T. Lillehei, Nano Lett. 2003, 3, 59.

[106] H. E. Miltner, N. Grossiord, K. Lu, J. Loos, C. E. Koning, B. Van Mele, Macromolecules $2008,41,5753$.

[107] N. Grossiord, J. Loos, L. van Laake, M. Maugey, C. Zakri, C. E. Koning, J. Hart, Adv. Funct. Mater. 2008, 18, 3226.

[108] B. Pradhan, K. Setyowati, H. Liu, D. H. Waldeck, J. Chen, Nano Lett. 2008, 8, 1142.

[109] M. Havel, K. Behler, G. Korneva, Y. Gogotsi, Adv. Funct. Mater. 2008, 18, 2322.

[110] J. T. Han, S. Y. Kim, J. S. Woo, G. Lee, Adv. Mater. 2008, 20, 3724.

[111] L. Valentini, S. B. Bon, J. M. Kenny, Macromol. Mater. Eng. 2008, 293, 867.

[112] H. Gu, T. M. Swager, Adv. Mater. 2008, 20, 4433.

[113] A. Ikeda, K. Nobusawa, T. Hamano, J. Kikuchi, Org. Lett. 2006, 8, 5489.

[114] J. Geng, B. S. Kong, S. B. Yang, S. C. Youn, S. Park, T. Joo, H. T. Jung, Adv. Funct. Mater. 2008, 18, 2659.

[115] M. Okamoto, T. Fujigaya, N. Nakashima, Adv. Funct. Mater. 2008, 18, 1776.

[116] J. Li, J. Qiu, J. Xu, H. Chen, X. Xia, Adv. Funct. Mater. 2007, 17, 1574.

[117] Z. Zhu, Z. Wang, H. Li, Appl. Surf. Sci. 2008, 254, 2934.

[118] Y. P. Sun, Nature 1993, 365, 398.

[119] H. Imahori, J. Mater. Chem. 2007, 17, 31.

[120] T. Hasobe, Y. Kashiwagi, M. A. Absalom, J. Sly, K. Hosomizu, M. J. Crossley, H. Imahori, P. V. Kamat, S. Fukuzumi, Adv. Mater. 2004, 16, 975.

[121] T. Hasobe, S. Fukuzumi, P. V. Kamat, Angew. Chem. Int. Ed. 2006, 45, 755.

[122] T. Umeyama, N. Tezuka, M. Fujita, S. Hayashi, N. Kadota, Y. Matano, H. Imahori, Chem.-Eur. J. 2008, 14, 4875.

[123] H. Zhang, L. Fan, Y. Fang, S. Yang, Chem. Phys. Lett. 2005, 413, 346.

[124] H. Zhang, L. Fan, S. Yang, Chem.-Eur. J. 2006, 12, 7161.

[125] Q. Wang, H. Moriyama, Langmuir 2009, 25, 10834.

[126] X. F. Zhang, T. V. Sreekumar, T. Liu, S. Kumar, J. Phys. Chem. B 2004, 108, 16435.

[127] P. M. Ajayan, L. S. Schadler, C. Giannaris, A. Rubio, Adv. Mater. 2000, 12, 750.

[128] M. F. Yu, B. S. Files, S. Arepalli, R. S. Ruoff, Phys. Rev. Lett. 2000, 84, 5552.

[129] A. Kis, G. Csanyi, J. P. Salvetat, T. N. Lee, E. Couteau, A. J. Kulik, W. Benoit, J. Brugger, L. Forro, Nature Mater. 2004, 3, 153. 
[130] D. Qian, W. K. Liu, R. S. Ruoff, Compos. Sci. Technol. 2003, 63, 1561.

[131] M. Olek, K. Kempa, S. Jurga, M. Giersig, Langmuir 2005, 21, 3146.

[132] A. Yu, M. E. Itkis, E. Bekyarova, R. C. Haddon, Appl. Phys. Lett. 2006, 89, 133102.

[133] G. Grüner, J. Mater. Chem. 2006, 16, 3533.

[134] L. Hu, D. S. Hecht, G. Grüner, Nano Lett. 2004, 4, 2513.

[135] E. Bekyarova, M. E. Itkis, N. Cabrera, B. Zhao, A. Yu, J. Gao, R. C. Haddon, J. Am. Chem. Soc. 2005, 127, 5990.

[136] J. Hone, M. C. Llaguno, N. M. Nemes, A. T. Johnson, J. E. Fischer, D. A. Walters, M. J. Casavant, J. Schmidt, R. E. Smalley, Appl. Phys. Lett. 2000, 77, 666.

[137] S. Shenogin, L. P. Xue, R. Ozisik, P. Keblinski, D. G. Cahill, J. Appl. Phys. 2004, 95, 8136.

[138] N. Shenogina, S. Shenogin, L. Xue, P. Keblinski, Appl. Phys. Lett. 2005, 87, 133106.

[139] M. Ouyang, J. L. Huang, C. M. Lieber, Acc. Chem. Res. 2002, 35, 1018.

[140] M. S. Fuhrer, J. Nygard, L. Shih, M. Forero, Y. G. Yoon, M. S. C. Mazzoni, H. J. Choi, J. Ihm, S. G. Louie, A. Zettl, P. L. McEuen, Science 2000, 288, 494.

[141] E. J. Garboczi, K. A. Snyder, J. F. Douglas, M. F. Thorpe, Phys. Rev. E 1995, 52, 819.

[142] Y. Wang, C. Di, Y. Liu, H. Kajiura, S. Ye, L. Cao, D. Wei, H. Zhang, Y. Li, K. Noda, Adv. Mater. 2008, 20, 4442.

[143] H. Z. Geng, K. K. Kim, K. P. So, Y. S. Lee, Y. Chang, Y. H. Lee, J. Am. Chem. Soc. 2007, $129,7758$.

[144] M. Zhang, Y. Yan, K. Gong, L. Mao, Z. Guo, Y. Chen, Langmuir, 2004, 20, 8781.

[145] B. L. Allen, P. D. Kichambare, A. Star, Adv. Mater. 2007, 19, 1439.

[146] G. Grüner, Anal. Bioanal. Chem. 2006, 384, 322.

[147] R. J. Chen, Y. Zhang, D. Wang, H. Dai, J. Am. Chem. Soc. 2001, 123, 3838.

[148] P. Diao, Z. Liu, J. Phys. Chem. B 2005, 109, 20906.

[149] Q. Wang, H. Moriyama, Bull. Chem. Soc. Jpn. 2009, 82, 743.

[150] M. L. Sham, J. K. Kim, Carbon 2006, 44, 768.

[151] Y. B. Wang, Z. Iqbal, S. Mitra, J. Am. Chem. Soc. 2006, 128, 95.

[152] N. P. Zschoerper, V. Katzemaier, Y. Vohrer, M. Haupt, C. Oehr, T. Hirth, Carbon 2009, 47, 2174.

[153] K. Peng, L. Q. Liu, H. Li, H. Meyer, Z. Zhang, Carbon 2011, 49, 70.

[154] M. J. Bleda-Martínez, D. Lozano-Castelló, E. Morallón, D. Cazorla-Amorós, A. LinaresSolano, Carbon 2006, 44, 2642.

[155] J. G. Zhou, C. Booker, R. Y. Li, X. T. Zhou, T.-K. Sham, X. L. Sun, Z. F. Ding, J. Am. Chem. Soc. 2007, 129, 744.

[156] K. R. Kissell, K. B. Hartman, P. A. W. Van der Heide, L. J. Wilson, J. Phys. Chem. B 2006, 110, 17425. 


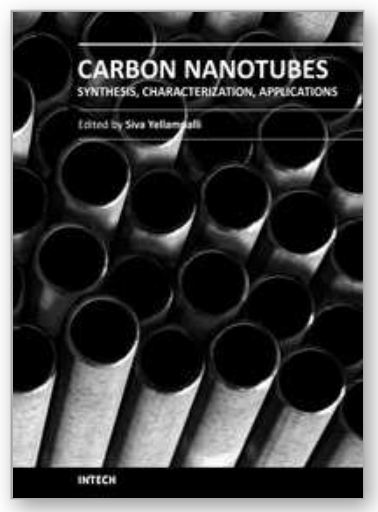

\section{Carbon Nanotubes - Synthesis, Characterization, Applications}

Edited by Dr. Siva Yellampalli

ISBN 978-953-307-497-9

Hard cover, 514 pages

Publisher InTech

Published online 20, July, 2011

Published in print edition July, 2011

Carbon nanotubes are one of the most intriguing new materials with extraordinary properties being discovered in the last decade. The unique structure of carbon nanotubes provides nanotubes with extraordinary mechanical and electrical properties. The outstanding properties that these materials possess have opened new interesting researches areas in nanoscience and nanotechnology. Although nanotubes are very promising in a wide variety of fields, application of individual nanotubes for large scale production has been limited. The main roadblocks, which hinder its use, are limited understanding of its synthesis and electrical properties which lead to difficulty in structure control, existence of impurities, and poor processability. This book makes an attempt to provide indepth study and analysis of various synthesis methods, processing techniques and characterization of carbon nanotubes that will lead to the increased applications of carbon nanotubes.

\section{How to reference}

In order to correctly reference this scholarly work, feel free to copy and paste the following:

Qiguan Wang and Hiroshi Moriyama (2011). Carbon Nanotube-Based Thin Films: Synthesis and Properties, Carbon Nanotubes - Synthesis, Characterization, Applications, Dr. Siva Yellampalli (Ed.), ISBN: 978-953-307497-9, InTech, Available from: http://www.intechopen.com/books/carbon-nanotubes-synthesischaracterization-applications/carbon-nanotube-based-thin-films-synthesis-and-properties

\section{INTECH}

open science | open minds

\author{
InTech Europe \\ University Campus STeP Ri \\ Slavka Krautzeka 83/A \\ 51000 Rijeka, Croatia \\ Phone: +385 (51) 770447 \\ Fax: +385 (51) 686166 \\ www.intechopen.com
}

\author{
InTech China \\ Unit 405, Office Block, Hotel Equatorial Shanghai \\ No.65, Yan An Road (West), Shanghai, 200040, China \\ 中国上海市延安西路65号上海国际贵都大饭店办公楼 405 单元 \\ Phone: +86-21-62489820 \\ Fax: +86-21-62489821
}


(C) 2011 The Author(s). Licensee IntechOpen. This chapter is distributed under the terms of the Creative Commons Attribution-NonCommercialShareAlike-3.0 License, which permits use, distribution and reproduction for non-commercial purposes, provided the original is properly cited and derivative works building on this content are distributed under the same license. 